\title{
Mothers' Perceptions of Their Children's Play: Scale Development and Validation
}

\author{
Lynn Barnett Morris \\ Dept. of Recreation, Sport and Tourism, 204N Huff Hall, 1206 S. Fourth Street, Champaign, IL 61820 \\ *Corresponding Author: lynnbm@illinois.edu
}

Copyright (C) 2013 Horizon Research Publishing All rights reserved.

\begin{abstract}
The wealth of literature that has investigated childrena's play behavior has largely relied on reports from mothers who have beliefs about the value of play for their child, and about how, when, and with whom their children should play. These beliefs and opinions influence the types of play opportunities, materials, and programs they provide, which in turn affect the childan's developmental trajectory and outcomes. The present study identified the issues that constitute parental beliefs about their childrenan's play, and developed a scale (the Mothersa' Perceptions of Their Childrenan's Play Scale) to measure them, with rigorous psychometric testing to establish its reliability and validity. The study was conducted on 698 mothers and their third through fifth grade child, and is the first to measure mothers' perspectives on their childrenan's play at this age. The findings of the study determined that there were two subscales a " mothers"beliefs about their childan's unstructured play and about their structured play a " both of which showed high internal reliability and temporal stability over a three month period, as did their component dimensions. Face, content and construct (concurrent, discriminant) validity were also found to be highly acceptable for the subscales and for the scale as a whole.
\end{abstract}

Keywords Mothers And Play, Childrena'S Play, Play Benefits, School-Aged Play, Middle Childhood

\section{Introduction}

A wealth of literature has been devoted to defining, classifying, describing, and examining children's play behavior $[1,2]$. The majority of this research has relied on observations of children involved in an activity, presumed to be play by the spectator[3]. These observations have been conducted by those trained to detectsigns of play, such as facial expressions (smiling), verbalizations (laughing, "this is fun"), or types of physical (running, jumping, climbing) or symbolic (using an object as if it were something else) activity. These presumptive indicators that children are indeed playing has come from the ubiquity of definitions and theories conceptualizing children's play as uniquely comprised of positive affect, nonliterality, and internal reward [4,5]. A plethora of research adopting an alternative approach to defining children's play has emanated from reports of parents who, while less articulate about the elements that comprise their identification of play, "know it when they see it" in their children[6,7]. Parents have basic beliefs about the value of play for their child, and about how, when, and with whom their children should play. These beliefs and opinions about play influence how they interact with their children, which in turn, affects the child's developmental trajectory and outcomes [6]. The extent to which parents value and perceive play determines how they organize their children's daily living context, from the objects found in their home (toys, play structures) to their daily routines, social interactions [8-11], and participation in out-of-school activities [12-15]. When parents believe that certain types or elements of play will benefit their child, the integration of play into the child's daily routine increases in quantity and quality[16].

The few studies that have been conducted examining parent beliefs about play have typically found a dichotomy that play is either viewed as important for the child's development in various ways, or as wasted time that could be devoted to more important endeavors, such as advancements in academic preparation[17-18]. For example, Fogle and Mendez [17]devised a scale to measure the play beliefs of African American lower class mothers with preschool children and found "Play Support" contrasted with "Academic Focus" in their two-factor solution. Haight, Parke, and Black [19] interviewed middle class Caucasian parents about their beliefs about their toddler's pretend play, rough-and-tumble play, and the importance of reading books to them, and whether all three play forms contributed to their child's development. They found that parents felt both pretend play and reading books contributed to their child's cognitive development, pretend play was important to their child's emerging understanding of social roles and relationships, and book reading was crucial for their future academic success. The parents who held these beliefs were 
shown to participate more actively in their child's play, and to encourage their toddler's play. The Haight et al. [19] data demonstrated that parents' beliefs influenced their interactions with their child and the messages that they transmitted about whether various play behaviors should be encouraged because they were important to the child's future.

While there is anabundance of studies that rely on parent reports as a measure of their children's play, there has been a paucity of research that directly delves into how parents perceive children's play - what issues are central to them when they think about and respond to questions about their child's play. When parents have been asked to provide information about their child's play, it has largely been the case that they are responding to specific questions that specify a definition, parameters, or contexts for their assessment. As in the Haight et al [19] study, both parents were interviewed about only three types of play and these were defined at the start of the session. With so much research utilizing parental perceptions of their child's play as a focal variable, it is critical to gain a more complete and unconstrained understanding of their perceptions and what issues comprise them. The present study represented just such an effort - the identification of the issues that constitute parental thoughts about their children's play, and the development of a scale to measure parental perceptions of their children's play and constituent components accompanied by rigorous psychometric testing to establish its reliability and validity. The study focused on mothers because previous research has found that their perceptions of, and interactions with, their children at play differs markedly from that of fathers [19-24]. In addition, for the age group under study (middle childhood), research has shown that it is the mother's values and beliefs that have been shown to carry the most weight [25] and that mothers have primary if not sole responsibility for initiating and arranging play dates, and for the choice of recreation programs in which to enroll children [13]. The sample was restricted to mothers of children in third through fifth grade, as there has been a paucity of studies conducted on mothers' views of their children's play for this age group, and because research has shown that children in their middle childhood years play differently than those of younger or older ages [1-2], which might reflect different maternal views of play.

To begin the process of constructing the Mothers' Perceptions of Their Children's Play (MPCP) Scale, focus groups of mothers convened to determine the content of the instrument. After several drafts, and reviews by child development experts, reliability, face, content, and construct validity testing ensued, following guidelines set forth by Nunnally and Bernstein [26]. Internal consistency and temporal stability (test-retest reliability) over a three-month time period were examined for the instrument as a whole and each of its component factors. Face and content validity were determined by an expert panel of researchers in child development, parenting, and children's play, and by third through fifth grade teachers and assistant principals.
Construct validity was determined by assessing relationships with the MPCP subscales and mothers' reports of the number, frequency and importance of children's unstructured and structured play,mothers' parenting style, and maternal tendencies toward gender stereotyping in the choice of play materials and activities provided for the child in this age range. Concurrent and discriminant validity were addressed through inspection of correlations between the MPCP factors and these measures, where it was anticipated that significant positive relationships would be shown with constructs similar to specific MPCP factors and negative relationships would be evinced with measures of constructs that were considered to be inversely related to particular MPCP factors. Convergent and discriminant validity were addressed by comparing the scores generated by mothers on each of the MPCP factors to their children's perceptions of their mothers' beliefs and rules about their play. Discriminant validity was also established by incorporating measures that should be unrelated to MPCP: children's nonverbal intelligence and academic achievement, and mothers' positive and negative affect and evidence of depression. Finally, we investigated whether there were any differences in the ways in which mothers viewed play as a function of the sex or age (grade) of their child.

\section{Materials and Methods}

\subsection{Participants}

Mothers of children in third, fourth, and fifth grade at six elementary schools in a medium-sized Midwestern city were contacted, and 698 mother-child dyads agreed to participate in the study. There was a fairly even distribution in the sample of mothers of children across grades, with $32.8 \%$ having children in third grade, $34.9 \%$ having children in fourth grade, and $32.3 \%$ were mothers of children in fifth grade. The majority of mothers were Caucasian $(82.2 \%)$, $6.8 \%$ were African American, $4.0 \%$ were Asian, $3.0 \%$ were Hispanic (non-White), $1.4 \%$ were bi-racial, and $2.6 \%$ declined to provide their race or ethnicity. A large percentage of the mothers were currently married or living in a significant long-term relationship (defined as more than five years) in which the focal child had been residing for at least the preceding five years $(79.6 \%) ; 14.8 \%$ were the sole parent in the home. Mothers ranged in age from 28 to 46 with a mean age of 35.76 years. The sample of mothers was highly educated compared with other Midwestern cities of the same size, with $23.8 \%$ having attended graduate school and $20.5 \%$ having earned an advanced degree; only $7.7 \%$ had never attended college or university. Most of the mothers were employed either part-time (less than 30 hours per week; $31.6 \%)$ or full-time $(46.8 \%)$, and of these mothers, their employment was predominantly outside the home (94.1\%). Annual household income for the sample members ranged from less than $\$ 15,000$ to over $\$ 500,000$, with a mean of $\$ 78,500$. All of the mothers in the sample responded 
affirmatively to an initial question asking if they were the one in the household who was primarily responsible for scheduling out-of-school play sessions, activities, and programs.

\subsection{Procedures}

As a first step, permission to conduct the study was obtained from the author's university and the school district administration to approach principals and third, fourth, and fifth grade teachers at individual elementary schools. Once approval and access was granted at all of these levels, sessions were held to explain to principals (or their designee) and third through fifth grade teachers the purposes and procedures of the study, respond to questions, and request their participation. Teachers were asked to distribute letters to their students to take home and give to their mother. The letter explained the purpose of the study and procedures, enumerated mother and child rights as participants in the study, provided contact information for approving agencies, and included permission forms for both mother and child, and information on how to obtain materials should consent be granted. Mothers were asked to return the consent forms in an enclosed envelope and give the envelope to their child to be placed in a marked box in their classroom that was retrieved on alternate days by a graduate student. Mothers and children were each offered a financial incentive for their participation. A total of 951 letters were distributed; 87 were returned with only the consent form signed by the mother (although 6 later declined when contacted to begin participation), and an additional 724 were returned with both signed consent forms. The mothers who provided only their own consent constituted the initial sample from which the first draft of the instrument was generated. A follow-up letter to each consenting mother and child provided directions to complete appropriate instruments, and both were offered the option of responding on printed or electronic forms (none of the participants chose this option). If the instruments had not been completed within two weeks of receipt of the letter, a follow-up postcard, e-mail, or telephone call was placed (depending on the respondent's indicated preferred method of contact). A third contact was initiated two weeks after the second if completed instruments had not been submitted. After six weeks from the date of the initial letter, 698 completed instruments had been received from mother-child dyads and formed the source of the data upon which later analyses were conducted.

\subsubsection{Initial Item Generation}

From those providing only their own consent, a total of 46 mothers(15thirdgrade, 15fourthgrade, 16 fifth grade)metduring evening hours to begin the process. Focus groups of 4 - 6 mothers within each of the grade levels were convened so that we might detect any differences in responses as a function of the grade/age of the child. Mothers were told we were interested in learning about what they generally thought about the play of children in third through fifth grade. They were asked to tell us about their views about the play of children of this age by providing whatever activities, descriptors, topics, or issues came to mind. Mothers' responses were all recorded and then transcribed verbatim for each grade and gender, and then reviewed by seven graduate students, blind to the purposes of the study, who independently noted the frequency of recurring themes and issues, as well as less common ones. The graduate students then assembled as a group with the researcher and compared the themes and lists across gender and grade levels, and no clear discernible differences were detected. Although no gender or grade differences were obvious to the group, this inference was statistically tested on the final version of the instrument. The entries were then combined and again checked for redundancy, clarity, and for alternate forms of wording, and 40 items were written to form a first draft from this "cleaned" list by the group and senior researcher. After an additional review to detect items with identical meaning, lack of clarity in wording, and terminology that might be confusing, 39 items comprised the second draft that was regarded as ready for pilot testing. A sample of 35 additional mothers who had provided consent but their child did not (12with third graders, 11 with fourth graders, 12 with fifth graders) independently reviewed this version of the instrument and provided feedback about any difficulties they had with the instructions, response scale, or the meaning or phrasing of individual words or items. They were told to circle any words or whole items that they found to be confusing or problematic and to write comments on the draft instrument where they wanted to inform us of any difficulties they encountered. On the basis of their feedback, the wording of three items was slightly revised, two were combined, and one was eliminated. A third draft of 37 items was returned to the same mothers for review, and in the absence of any questions or negative comments about readability, comprehension, or instructions for completion, the third draft was submitted to and independently reviewed by a 15-member expert panel (four child development researchers, three third grade, fourth grade, and fifth grade teachers, and two elementary school assistant principals). The results of the expert panel's assessment were that one item should be revised and one eliminated. This semi-final version consisted of 36 items to which 698 mothers, none of whom were involved in the preparation of the drafts of the instrument, were asked to respond using a 6-point Likert scale: ranging from "strongly disagree" (scored 1), "mostly disagree" (scored 2), "somewhat disagree" (scored 3), "somewhat agree" (scored 4), "mostly agree" (scored 5), and "strongly agree" (scored 6) for all items.

\subsection{Measures and Instruments}

The measures and instruments described below were adopted to test the construct validity of the Mothers' Perceptions of Their Children's Play (MPCP) Scale. Several of the instruments and measurements that were selected to establish construct (concurrent and discriminant) validity 
more specifically addressed one or more of the factors rather than the instrument as a whole. This procedure was adopted in the absence of any existing measures against which to compare the total scale scores, and because the individual factors comprising the total instrument were shown to be orthogonal and to each independently possess high internal consistency and stability over a three-month time period.

\subsubsection{Parenting Style}

Parenting style was assessed utilizing the typology that emerged from Baumrind's [27-30] and others' [31] research based on differences in the constructs of parental warmth and control. Of particular interest in this study were the authoritarian and authoritative parenting styles. The authoritarian parenting style reflects the assertion of power without warmth, nurturance, or communication with the child. A mother with an authoritarian parenting style would attempt to control and evaluate the behaviors and attitudes of their children against her rigid set of standards, valuing, above all, obedience to her dictates, and respect for her authority [32]. Parents who are authoritative also set firm controls on the behavior of their child but are willing to listen to the child's point of view and adjust their behavior accordingly. A mother who possesses an authoritative parenting style would demonstrate warmth, nurturance, open parent-child communication, and a democratic approach to decision-making and would actively solicit the child's opinions and feelings about an issue[32]. These parenting styles have been found to be fairly constant across time and contexts [33-34].

Scales assessing authoritarian and authoritative parenting styles were taken from the Parenting Practices Questionnaire (PPQ) [35]. The authoritative scale consists of 27 items assessing warmth/involvement (e.g., "gives comfort and understanding when the child is upset"), reasoning/induction (e.g., "emphasizes the reasons for rules"), democratic participation (e.g., "allows the child to give input into family rules"), and good natured/easy going (e.g., "shows patience with the child"). The 20 -item authoritarian scale is a compilation of verbal hostility (e.g., "yells or shouts when the child misbehaves"), corporal punishment (e.g., "uses physical punishment as a way of disciplining the child"), no reasoning/punitive strategies (e.g., "uses threats of punishment with little or no justification"), and directiveness (e.g., "demands that the child does things"). Response choices for both scales range from "never" (scored ' 1 ') to "always" (scored ' 5 '). Both scales have been found to show high internal consistency (range of .77 to .91) and construct validity in previous research [32,35-37]. In the present study, alpha coefficients were .86 and .91 for the authoritarian and authoritative scales, respectively. A mean score for each scale comprised the parenting style variables used in the analyses.

\subsubsection{Gender Stereotyping}

An independent measure assessing mothers' attitudes about the gender-appropriate behavior of children was derived from the Sex-Bias Parenting Style (SB) subscale of a larger questionnaire measuring parents' views and beliefs about child-rearing $[38,39]$. Mothers were asked to respond to the 18-item scale (e.g., "It is more acceptable for girls than for boys to engage in rough-and-tumble play" and "Boys should be given as much opportunity as girls to play with dolls if they wish") using a 5-point Likert scale ("strongly disagree" to "strongly agree"), with high scores denoting more sex-biased attitudes. Previous research has found acceptable internal consistency for the scale $(\alpha=.87$ and $\alpha$ $=.76$ on two different samples) [38)], as well as in the present study $(\alpha=.90)$.

\subsubsection{Depression}

Depression in mothers was assessed using the Beck Depression Inventory (BDI-II), which is a widely used and validated measure of self-reported depression for persons aged 13 years and older[40]. Respondents are presented with a series of 21 statements and asked to indicate which response they think is most appropriate for them. The scores of each question range from 0 to 3 , and are summed to yield a total depression score. The coefficient alpha for the BDI-II for mothers in the present study was .92, which compares well to that of .87 obtained in an earlier research study with a nonclinical adult population [40].

\subsubsection{Positive and Negative Affect}

The PANAS Scales were developed to assess positive and negative affect with each assessed with a 10-item scale [41]. Each scale consists of single words to which the individual is asked to respond with the extent to which $\mathrm{s} / \mathrm{he}$ has felt this way using the response choices of "very slightly or not at all", "a little", "moderately","quite a bit", or "extremely". The scales have been shown to be highly internally consistent (alpha coefficients for the positive affect scale were.89 and for the negative scale.85), and stable over two-month ( $\mathrm{r}=$ -.87 on both positive and negative affect scales) and one year $(\mathrm{r}=.86$ for positive affect and .84 for negative affect) periods of time. Normative data and factorial and external evidence of convergent and discriminant validity for the scales are all well-documented [41]. The scale has been used to capture both transient (state) affect and general affect (trait) by varying the instructions asking participants to respond according to how they felt at the moment or generally. In the present study we chose to assess mothers' positive and negative affect more generally to demonstrate that the MPCP scale was not subject to temporary mood states. Coefficient alpha for our sample of mothers was .90 for the positive affect scale and .88 for the negative affect scale.

\subsubsection{Children's Participation in Out-of-School Play Activities}

Mothers were presented with an inventory of 56 possible play activities derived from the initial focus groups of mothers of children of this age. For later coding purposes, each activity was categorized as "structured" (organized) or "unstructured" (free) play. The definition of "structured" 
play was adopted from that agreed upon by several scholars [42-44] as activities that are voluntary, meet at regular and scheduled times, offer supervision and guidance from adults, and are organized around developing particular skills and achieving goals. Free, or unstructured activities, are more spontaneous, are not guided or supervised by adults but instead are largely determined by and under the continuous control of the players, may be loosely organized and with frequent agreed-upon changes, are often nonliteral with frequent elements of pretense, and are motivated primarily by the goal of seeking fun and amusement for the participants $[1,2,4,45]$. Each activity was categorized as "structured" or "unstructured" by seven graduate students working independently who were naïve to the purpose of the study but provided with the definitions for these two general play categories. The labels assigned to activities were reviewed by the raters as a group, and discrepancies were resolved by weighing correspondence with the definitions provided. Initial agreement among the coders $($ Kappa $=.88)$ was "almost perfect" [46]; after resolving any discrepancies and recalculating Kappa, agreement reached .99 .

\subsubsection{Number of Activities and Frequency of Activity Engagement.}

A frequency of play activity measure was obtained from mothers' reports of how often the focal child engaged in each activity ("How often does your child do each of the following things?"). Mothers rated frequency for each activity using a 6-point scale, where 1 = "less often/never", 2 = "once a month", 3 = "a few times a month", $4=$ "about once a week", 5 = " 2 to 4 times a week", and $6=$ "every day or almost every day" [6]. Three dependent variables were derived from the responses to the frequency measure. The first was a count of the number of activities in which the child engaged at least once a month (the activity was counted if given a score of ' 2 ' or higher), providing an indication of the diversity, or breadth, of activities in which the child participated. A separate count was taken for the numbers of structured and unstructured activities. Three additional dependent variables consisted of the mean frequency scores across all activities, as well as the frequency of "structured" (e.g., "playing on a sports team" or "going to a dance class") and "unstructured" (e.g., "playing outside" or "getting together with a friend to play") play. These latter variables reflected the child's degree of involvement (amount of time spent) in structured and unstructured out-of-school play activities.

\subsubsection{Importance of Activities.}

Mothers were also asked to indicate how important they felt it was for their child to engage in each activity. This variable was meant to provide an indication of how mothers felt about their child's various play activities, and whether they were perceived as serving a valuable purpose for the child. Previous research has shown that mothers attribute a wealth and diversity of beneficial outcomes to children's structured and free play, ranging from boosting academic success, to teaching social skills and negotiation, to enhancing creative talent, to building character and self-esteem [43,47-52]. A 5-point Likert response scale was provided, with anchors of "not at all important" (scored '1') to "extremely important" (scored ' 5 '). A mean importance score across all activities was calculated, as were separate mean total scores for structured activities and unstructured activities.

\subsubsection{Children's Perceptions of Their Mother's Beliefs and Practices about Their Play}

Once the final version of the MPCP was generated and pilot tested, questions that were comparable to most of the MPCP items were adapted for the children. We reasoned that the ways in which mothers viewed their children's play would be communicated clearly and explicitly to the children, and that the correspondence between mothers' and children's ratings could be regarded as an indicator of the strength with which mothers held and conveyed their beliefs. In addition, we also regarded the degree of correlation between mothers' and children's scores as reflecting the extent to which a social desirability bias might have been present in the way that mothers answered the items on the questionnaires.

An instrument was developed ("Children's Perceptions of Their Mother's Beliefs and Practices About Their Play"; CPMBP) consisting of statements to pose to the children about how they thought their mother would respond to certain play choices or situations. An initial draft of 31 items came from efforts to preserve the meaning and at the same time adapt each of the items in the final version of the MPCP to the age of the children in the study. After intensive scrutiny by an expert panel of 15 child development and play scholars and third through fifth grade teachers and administrators, the number of items was reduced to 30 (one was considered redundant) that were deemed to be comparable to the version developed for mothers. The agreed-upon response scale for this age range consisted of five choices labeled "strongly agree" (coded '4'), "somewhat agree" (coded ' 3 '), "somewhat disagree" (coded '2'), "strongly disagree" (coded ' 1 ') and "don't know" (coded as missing data).

Children were instructed to answer the 30-item CPMBP when they had some free time and were alone. They were provided with an electronic version and told that if they had any difficulty they could receive a hard copy to complete, or they could contact the researcher with questions or problems. They were assured that neither their parent nor their teacher would see their responses, and an arbitrary number would be put on their answer sheet so they couldn't be identified (but could be matched to their mother's responses).

\subsubsection{Nonverbal Intelligence}

All of the children completed the Naglieri Nonverbal Ability Test (NNAT) [53,54] which was designed to be a brief, culture fair nonverbal measure of intelligence that has good psychometric properties for children aged kindergarten through $12^{\text {th }}$ grade, across different racial, ethnic, and 
socioeconomic backgrounds, and countries of origin [55]. Children are not required to read, write, or speak; the test is comprised of "progressive matrix items that use shapes and geometric designs interrelated through spatial or logical organization" [55, p. 330]. Children are asked to examine the relationships among the elements in the matrix and determine which of the given responses is correct. There are a total of seven levels, each with items appropriate for children at that grade level as well as adjacent higher and lower levels. A score is given based on the number of correct responses; higher scores indicate higher nonverbal intelligence. High internal consistency for this measure was obtained for the children in this study $(\alpha=.92)$, and was comparable to that (range $=.83$ to .93 ) found in other studies [54-55].

\subsubsection{Academic Achievement}

Children's academic achievement was measured by their scores on the mathematics and reading comprehension subscales of the Test of Academic Performance (TAP)[56] for kindergarten through $12^{\text {th }}$ grade students (the full battery also includes spelling and writing scales). The reading comprehension subtest asks children to read two grade appropriate passages and answer four questions about each one. For the mathematics subtest, children must complete 45 computations/equations appropriate for their grade level. The TAP has been shown to have good psychometric properties [57]; internal consistency in the present study was .89 for the mathematics scale and .78 for the reading scale.

\section{Results}

\subsection{Development of the Instrument: Items and Factors}

The analysis of the Mothers' Perceptions of Their Children's Play (MPCP) Scale occurred in several steps. First, intercorrelations between the individual items and corrected item-total correlations were generated for the 36-item scale. Using the guidelines recommended by Nunnally and Bernstein [26], an item was considered "weak" if it had a corrected item-total correlation that was less than .30. Only one of the items failed to meet this criterion and it was deleted from the instrument - all other items had corrected item-total correlations that exceeded .41 (range $=.41$ to .83$)$.

In the next step, the scale was subjected to a principal-axis factor analysis (PAF) with oblique rotation due to intercorrelations among the items. The rotation allowed for an examination of the structure matrix in order to determine the relationship of each item to the factor; absolute values of .40 or higher were considered significant in interpretation [58]. All but one of the items had a significant loading on at least one factor and low loadings on all others; the item with multiple cross-loadings on several factors was removed from the instrument even though its item-total correlation was acceptable. Following the suggestion by Floyd and Widaman [59], the remaining 34 items were then subjected to a second $\mathrm{PAF}$ and alpha coefficients were re-computed. All item-total correlations continued to exceed the .30 minimum criterion (range $=.43-.75)$

The PAF revealed seven first-order factors: "Play Freedom," "Maternal Rules," "Play Safety," "Imaginative Play," "Gender Typing," "Importance" of OSSPs, and "Child's Choice" in OSSPs. These seven factors explained a relatively large amount of variance $(81.06 \%)$, and the correlations between them suggested that the seven factors might be indicative of one over-arching MPCP factor. We thus tested the seven-factor solution (Model 1, see Figure 1) and compared its goodness-of-fit to a second model with a single higher-order factor (Model 2, see Figure 1). In addition, upon closer inspection of the items within the factors, it appeared that five factors were more closely related to children's free time and two appeared to more obviously reflect structured recreational activities. This suggested that a third model (Model 3, see Figure 1) in which two second-order factors of Unstructured (Free) Play (consisting of "Play Freedom," "Maternal Rules," "Play Safety," "Imaginative Play," "Gender Typing") and Out-of-School Structured Play (consisting of "Importance" and "Child's Choice") might be a better fit to the data. We then drew on the vast literature surrounding mothers' gender stereotyping their children's play through the provision of play materials and recreational activities in which they enrolled their children [13,60-62]. We wondered whether the "Gender Typing" factor was thus a separate way of thinking about play in relation to the other factors, or if it reflected clear distinctions about what types of play ("play styles") were communicated to children as sanctioned. We tested two additional models that reflected different ideas about how mothers thought about Gender Typing in relation to the other factors - whether it was indicative of their opinion about permissible play styles (Model 4, see Figure 1), or whether it represented a distinctive perspective altogether (Model 5, see Figure 1). We reverse coded each of the items comprising the "Gender Typing" factor so that they were consistent with the interpretation for the other factors. All five models were tested with maximum likelihood confirmatory factor analyses (CFAs). Fit statistics guidelines used to confirm the dimensionality of the solutions from the PAF that were utilized were: a non-significant chi-square $(p>.05)$ when sample sizes are $\geq 250$, root-mean-square error of approximation (RMSEA) values below .05, and a comparative fit index (CFI) value above .90 [63]. The results of the CFA for each of the five models are shown in Figure 1, and indicate that Model 3 provides the best fit to the data. This indicates that mothers perceived a distinction between their child's free play and structured programmatic activities. That this model best fit the data also provided evidence that mothers regarded the five free play factors as equally weighted dimensions comprising their perspectives on this aspect of their children's play. 
1. Frdm Rules Safety Imagn Gendr Imprt Choice $\begin{array}{ccc}\chi^{2} & C F I & R M S E A \\ 21.26 & .78 & .17\end{array}$

2.

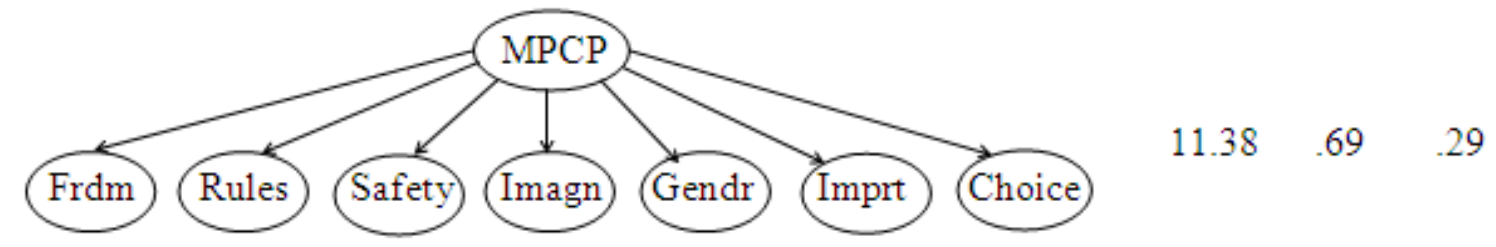

3.

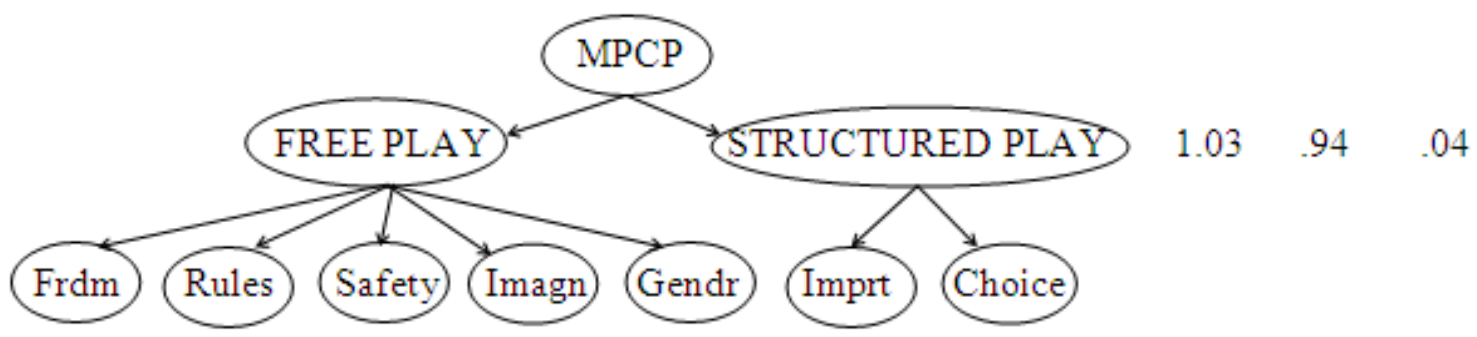

4.

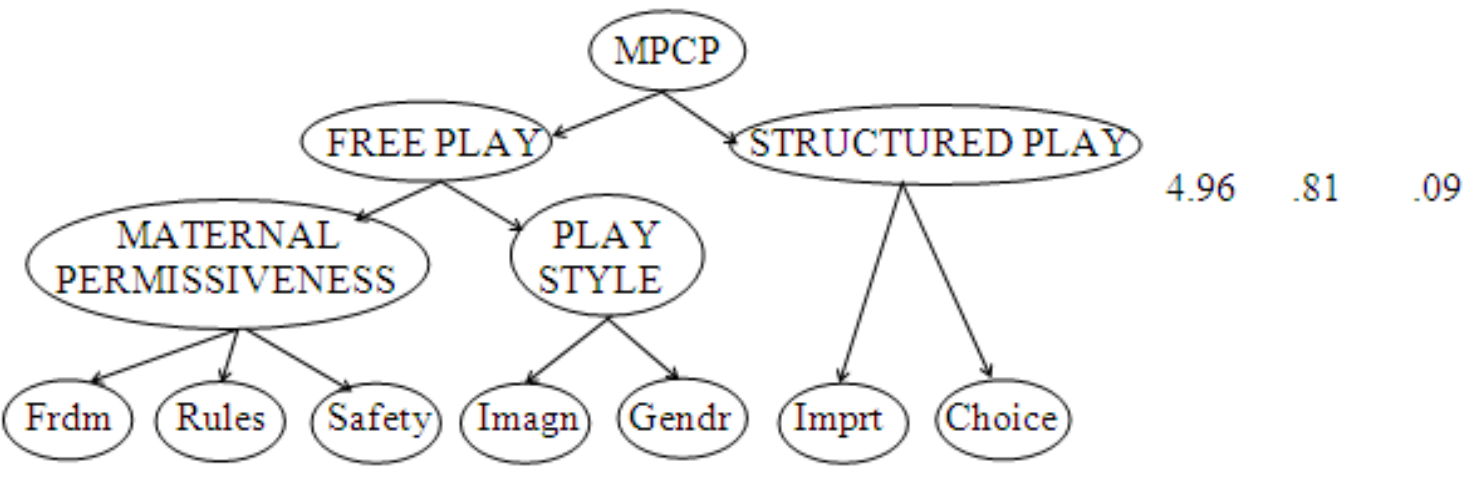

5.

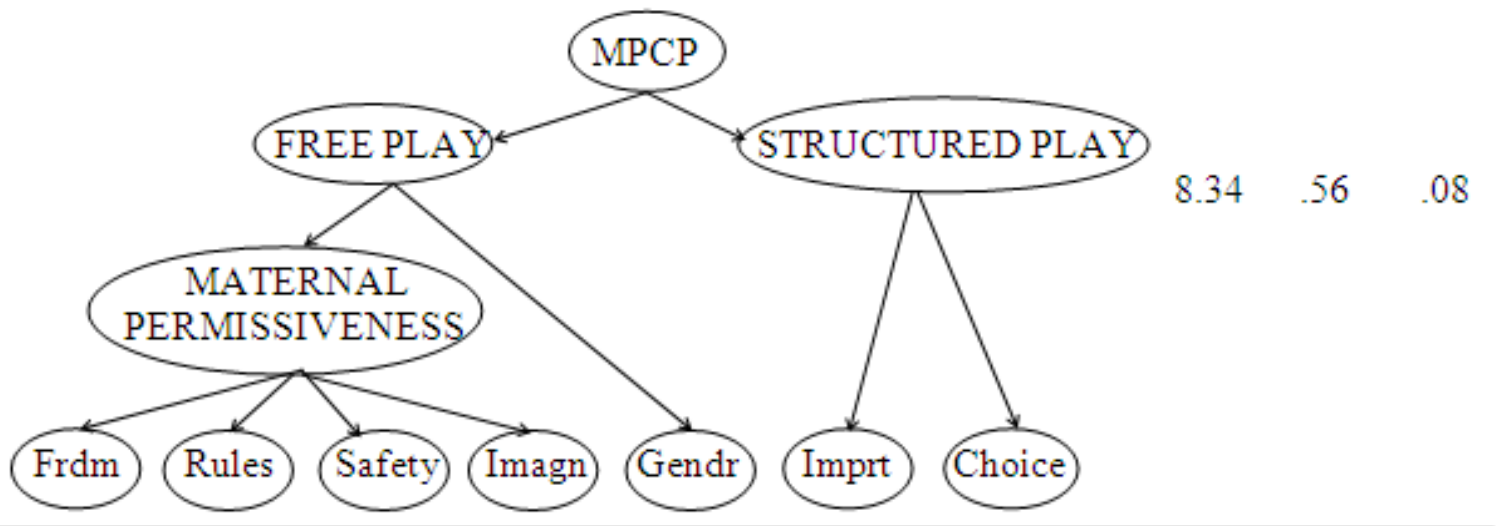

Note CFI = Comparative Fit Index; RMSEA = Root-mean-square Error of Approximation, Frdm = Play Freedom, Imagn = Imaginative Play, Gendr $=$ GenderTyping, Imprt = Importance

Figure 1. Fit Indices for Confirmatory Factor Analysis of the MCPC Scale 
Table 1. Results of Factor Analysis and Reliability Tests for Mothers' Perceptions of Their Children's Play Scale Items

FREE PLAY

\begin{tabular}{|c|c|c|c|c|c|c|}
\hline \multicolumn{5}{|c|}{ FREE PLAY } & \multicolumn{2}{|c|}{ STRUCTURED PLAY } \\
\hline "Play & "Matemal & "Play & "Imaginative & "Gender & "Impor- & "Child's \\
\hline Freedom" & "Rules" & "Safety" & $=\quad$ "Play" & Typing" & tance" & Choice" \\
\hline I. & II. & III. & IV. & V. & VI. & VII. \\
\hline .8311 & -.2140 & -.1156 & .2317 & -.2011 & -.1559 & .2487 \\
\hline .8102 & -.0114 & .0028 & .1898 & .0014 & .0004 & .1244 \\
\hline .7204 & -1916 & .0109 & .1485 & .0187 & .0112 & .1882 \\
\hline .7417 & -.2556 & -.1994 & .0323 & -.2961 & -.0387 & .2014 \\
\hline .7918 & -.2545 & .2898 & .3114 & .1874 & -.0823 & .0759 \\
\hline .6825 & -.2953 & .0771 & .1162 & .0041 & -.2100 & .0311 \\
\hline-.7882 & .1821 & .1917 & -.2217 & .0470 & .1056 & -.1742 \\
\hline .1172 & .7551 & .3307 & .1728 & .2147 & .1725 & -.0879 \\
\hline .0035 & .8102 & .2814 & .0995 & .1563 & .1439 & .0621 \\
\hline-.0078 & .7269 & .2990 & -.1143 & .1156 & .0991 & -.1429 \\
\hline-.2940 & .6961 & .1863 & -.2128 & -.1879 & -.1462 & -.1240 \\
\hline-.2561 & .7008 & .1755 & -.2744 & .2478 & .1824 & .0078 \\
\hline .2682 & -.2044 & -.8611 & .1078 & -.2176 & -.1876 & -.1547 \\
\hline-.1422 & .2016 & .8094 & .0801 & .1679 & .2217 & -.0025 \\
\hline
\end{tabular}

Item

1. Children should be given a lot of freedom to decide how they want to play.

2. Children should be allowed to take their toys apart,

3. Children should be able to decide when to share their toys and when not to.

4. Children should be allowed to play with whomever they please.

5. Children should be allowed to play anywhere in the house as long as their health and safety are not endangered.

6. Children should be allowed to watch TV whenever they want to.

7. A child using a toy in the wrong way should be corrected. $^{*}$

8. There are certain rooms that should be off limits to children when they play.

9. Children should not be allowed to leave their toys around the house.

10. A lot of discipline is essential in raising children.

11. Children should play with toys the way they are meantto be used.

12. It is important that children follow the rules of the game when they play.

13. School-age children should be allowed to play without supervision. ${ }^{8}$

14. Physical play should be allowed only outdoors or
$-1422$ 
in designated areas.

15. It's important to watch out for the safety of my $\quad \begin{array}{llllllll}-.1889 & .2871 & .8149 & .0560 & .1847 & .2111 & -.2669\end{array}$ child when he or she is playing.

16. Children can easily get hurt when they're playing. $\quad-2146$

17. It is good for children to play make-believe games. $\quad .2664$

18. Parents should be worried if their child has an $\quad-.2810$ imaginary playmate.

19. It is all right for children to get dirty once in a while. .3122

20. Children should be allowed to make a mess just .305 for the fun of it.

21. Boys should be discouraged from playing with girls' -.2159 toys and games.

22. Girls should be discouraged from playing with boys' -.2568 toys and games.

23. Boys should be encouraged to only participate in $\quad-.2491$ boys' kinds of play activities.

24. Girls should be encouraged to only participate in $\quad-.2403$ girls' kinds of play activities.

25. Children can leam a lot by being in organized $\quad .0034$ activities.

26. Organized after-school activities are an important $\quad-.0118$ part of my child's education.

27. It is important for children to be involved in $\quad-.2599$ activities when they are not in school.

28. It is important that children learn to use their time $\quad-.1941$ wisely.

29. I like my child to be kept busy with lots of activities -.1743 when he/she is not in school.

30. It is important for children to have free time to do $\quad .2810$ whatever they wish."

31. Parents should take an active role in setting up $\quad-.1866$ activities for their child when they are not in school.

32. Children should have a say in what they do after

.2779

.1171

.0021

.7602

.1698

.0002

$.0877 \quad .1021$

$-.1993 \quad .0649$

$.1829 \quad .0038$

.1246

$-.0007$

.0822

.0341

.1674

.0336

.1103

.0874

.0310

.1921

.0872

$-.1320$

.0064

.1232

$-.1833$

\section{.0998}

.8611

$-.8731$

.1996

0301

.1892

.2387

.1286

$-.1719$

$-.0078$

.1497

$-.1910$

$\begin{array}{llll}.8222 & .0723 & .1577 & .1621\end{array}$

$\begin{array}{llll}.7998 & -.0071 & .1729 & .0076\end{array}$

.016

.8014

.012

$-.1249$

$-.0198$

.7613

.0047

$-.2071$

.0781

.8412

.1179

$-.2265$

$-.0211$

.7129

.0008

$-.1994$

$-.1044 \quad .1378$

.8611

.1341

$-.1612 \quad .1045$

.8320

.1762

$-.2017 \quad .0892$

.7418

.1481

$.0043 \quad .0241$

.6844

.0238

$-.2155 \quad .1147$

.6449

.1852

$.2040 \quad-.0199$

$-.6317$

.3018

$.0002 \quad .2044$

.6418

.0491

$\begin{array}{lll}.1823 & .1258 & .1547\end{array}$

.8861 
school hours.

33. Children usually know best what out-of-school activities they will get something out of.

34. Children should be allowed to decide for themselves if they want to be in an organized activity after school hours.

35. Children should have more say in deciding what activities the community should arrange for them.

36. If children are unhappy doing an out-of-school activity, they should be allowed to quit.

$\begin{array}{lccccccc}.1182 & -.0239 & .1052 & .1429 & -.0045 & .0029 & .6832 \\ .1778 & -.0008 & .0674 & .1667 & -.0006 & .0385 & .8211 \\ & & & & & & \\ .1143 & .0107 & .0249 & .1722 & .0401 & .1745 & . \mathbf{8 0 1 6} \\ & & & & & & \\ .0825 & -.1556 & .1299 & .1485 & .1005 & -.1255 & .7471 \\ & & & & & & \\ & & & & & & \\ 3.9861 & 2.4510 & 1.4122 & 1.2923 & 1.2287 & 3.1867 & 1.3207 \\ 31.90 & 17.81 & 11.26 & 10.74 & 9.81 & 47.30 & 31.96 \\ 31.90 & 49.71 & 60.97 & 71.71 & 81.52 & 47.30 & 79.26 \\ & & & & & & \\ 8917 & .9091 & .8482 & .8291 & .8349 & .8240 & .8496 \\ 8610 & .8594 & .7816 & .7721 & .8034 & .7796 & .7220\end{array}$

*inverted coding for reliability calculations 
The results of the PAF analysis showing the factor loadings for the 34 items for the seven factors are presented in Table 1. The eigenvalues and unique and cumulative explained variance are presented separately for the first-order factors. As can be seen, the eigenvalues were all above one, each of the factors uniquely contributed at least $10 \%$ to the variance, and the curve leveled out according to the scree test [64] after these factors were extracted. The five factors comprising the Play subscale collectively accounted for $81.52 \%$ of the total variance; the two factors constituting the OSSP subscale cumulatively contributed $79.26 \%$ to its total variance. The instrument as a whole accounted for $80.71 \%$ of the total variance.

The first Play factor, labeled "Play Freedom", was comprised of seven items and contributed the largest portion to the variance $(31.90 \%)$. It addressed children's freedom to determine their own play activities, partners, and style. The second "MaternalRules" factor, containing three items and contributing $17.81 \%$ to the variance, isolated the items that stressed the child following rules when at play and the general use and acceptance of discipline in setting limits for children. The third factor was labeled "Play Safety" and appeared to capture mothers' concerns for the safety of their playing child by setting restrictions about where children could play and the need for supervision. There were four items comprising this Play factor, adding $11.26 \%$ to the total variance. The "Imaginative Play" factor, with four items contributing $10.74 \%$ unique variance, showed high loadings on items reflecting mothers' beliefs that imaginary play and playmates, and a lack of concern for getting dirty or making a mess were all positive aspects of play. "Gender Typing" was comprised of four items that collectively revealed mothers' opinions about whether children of one sex should be allowed to play with toys and in ways deemed traditionally appropriate for the opposite sex; high scores indicated the perception that mothers perceived there are strict appropriate norms for the play of boys versus girls and that these should be followed. When a total MPCP scale score or total Unstructured(Free)Play subscale score was desired, the Play Rules, Play Safety, and Gender Typing items were reverse coded (with the exception of those noted as inverted coding in Table 1). This permitted an interpretation of either the total MPCP scale or total Unstructured Play subscale score to be such that higher values indicated that mothers held a more open and permissive mindset about their children's play.

The two factors that comprised the Out-of-School Structured Play Activities subscale were labeled "Importance" and "Child's Choice" and the combination of these two factors collectively accounted for $79.26 \%$ of the total variance. The "Importance" factor indicated whether mothers thought it was important that their child participate in out-of-school structured play activities. The seven items comprising this "OSSP Importance" factor collectively accounted for almost one-half of the total explained variance for this subscale. The five items comprising the "Child's Choice" factor assessed the extent to which mothers thought their children should be allowed to choose whether or not to participate in OSSPs, and in which particular types. The items that loaded highly on this factor collectively constituted almost one-third of the total variance for the OSSP subscale.

\subsection{Reliability}

The reliability of the final version of the MPCP was tested in two ways. First, the internal consistency of the scale as well as each of the factors was computed. The scale as a whole was found to have satisfactory internal consistency ( $\alpha$ $=.84$ )after inverting the coding on the items comprising the Play Rules, Play Safety, and Gender Bias factors (except on items shown as inverted in Table 1). Internal consistency alpha coefficients were also calculated individually for each of the factors with only the designated items (see Table 1) inverted. Each of the component factors of the MPCP was found to be high in internal consistency (range $=.82$ to .91 , see Table 1) according to the criterion that an alpha value above .80 is regarded as "good" [65]. Alpha coefficients between .80 and .90 are considered optimal in demonstrating that the items are strongly related and that each item simultaneously contributes unique information; a result above .95 is undesirable as it indicates redundancy and that several items are superfluous [66]. Test-retest reliability was also assessed over a 3-month time span and was found to be .80 for the instrument as a whole, and to show stability as well for each of the component factors (range $=.72$ to .86 , see Table 1).

\subsection{Face Validity}

Face validity, an elementary and often initial approach to establishing the validity of a test, concerns whether the test appears to measure what is intended to measure[67]. To establish the face validity of the MPCP Scale, we first asked members of our panel (researchers, teachers, assistant principals) what they thought our test was attempting to measure. Each replied back to us correctly - that we were trying to generate a measure of how mothers felt about their children'splay. Not one of the fifteen members of the panel provided an alternative response - it appeared that our items were quite transparent in conveying the purpose of the scale. We concluded from the unanimous replies that the scale was high in face validity. We interpreted this as a good starting point and proceeded to look within the scale in more depth to examine its content and construct validity.

\subsection{Content Validity}

Content validity refers to whether the instrument adequately samples the domain of content, that is, it addresses the question, "Do the items on the instrument comprehensively represent all of the aspects of mothers' perceptions of their children's play?" Content validity is achieved by the consensus of judges - subject matter expert raters - who respond to the following question for each item: 
"Is the skill or knowledge measured by this item 'essential,' 'useful but not essential,' or 'not necessary' to the performance of this construct?" [68]. The 15 members of our expert panel each independently responded to this question in relation to the topic under scrutiny - mother's perceptions of their children's play - and Lawshe's [68]formula for determining content validity was applied: $C V R=\left(n_{e}-N / 2\right) /$ $(\mathrm{N} / 2)$, where $\mathrm{CVR}=$ content validity ratio, $\mathrm{n}_{\mathrm{e}}=$ number of SMEs indicating "essential", $\mathrm{N}=$ total number of SMEs. The mean CVR across items is used as an indicator of the overall content validity of the instrument. Utilizing Wilson, Pan, and Schumsky's [69] corrected table of critical values for CVR, the instrument was found to be content valid at the .001 level of significance $(\mathrm{CVR}=.803)$.

\subsection{Construct Validity}

Relationships (heterotrait-monomethod correlations) between scores on the MPCP and on the following measures all completed by mothers were used to examine convergent validity: authoritarian and authoritative parenting styles, the number of structured and unstructured play activities in which the child participated at least once a month, the mean frequency and perceived importance of the child's participation in both types of play activities, and the extent to which mothers were prone to gender stereotyping their child. Convergent validity was addressed by examining the correlations between measures and MPCP factors that should show significant positive relationships; discriminant validity was shown by significant negative relationships between inversely related measures and specific MPCP factors and also by the absence of a relationship with variables that were hypothesized to be unrelated: mothers' depression and positive and negative affect, and children's academic achievement and nonverbal intelligence. Convergent and discriminant validity were also addressed by comparing the scores generated by mothers on each of the factors to those of their children (monotrait-heteromethod correlations) who would be responding based on the extent to which mothers were consistent and transmitted their beliefs about their children's play to their children.

\subsubsection{Convergent and Discriminant Validity: Monomethod Correlations}

Zero-order correlations were computed between the MPCPcomponent factors and each of the construct validity criterion measures that were completed by mothers (Table 2). As can be seen from the Table, virtually all of the correlations were highly statistically significant $(p<.001)$; only two reached significance at the .01 level, and none were at a lower alpha level. Because several of the criterion measures were specifically selected to demonstrate stronger relationships with certain MPCP factors (for example: Unstructured Play and Play Freedom factor, Structured Play and Play Rules and Play Safety factors, Sex Bias Scale and Gender Typing factor) more than others, the correlations for these assessments of concurrent validity by factor are underscored in the Table. To control for family-wise Type I errors given the large number of correlations being conducted, the significance level for discussion and interpretation was set at an alpha level of .001 rather than adopting adjustments using the Bonferroni or Holm method which have been criticized as being too severe [70-71].

Table 2. Correlations(decimals omitted) Between MPCP Factors and Construct Validity Measures

\begin{tabular}{|c|c|c|c|c|c|c|c|}
\hline \multirow[b]{2}{*}{ Construct Validity Measures } & \multicolumn{5}{|c|}{ FREE PLAY } & \multicolumn{2}{|c|}{ STRUCTURED PLA } \\
\hline & Freedom & Rules & Safety & Imagin & Gender & Imprtnc & Choice \\
\hline Number of Play Activities & $69^{2}$ & $-22^{2}$ & $-39^{2}$ & $\underline{57^{2}}$ & $18^{2}$ & $71^{2}$ & $66^{2}$ \\
\hline Number of Structured Play Activities & $\overline{31}^{2}$ & $\underline{43}^{2}$ & $58^{2}$ & $-19^{2}$ & $47^{2}$ & $\underline{81}^{2}$ & $24^{2}$ \\
\hline Number of Unstructured Play Activities & $\underline{66}^{2}$ & $-\overline{28^{2}}$ & $-\overline{17}^{2}$ & $42^{2}$ & $\overline{25^{2}}$ & $-09^{1}$ & $51^{2}$ \\
\hline Time in Play Activities & $72^{2}$ & $25^{2}$ & $51^{2}$ & $66^{2}$ & $-17^{2}$ & $64^{2}$ & $\underline{61^{2}}$ \\
\hline Time in Structured Play Activities & $\overline{24}^{2}$ & $\underline{61^{2}}$ & $\underline{69^{2}}$ & $-23^{2}$ & $\underline{56}^{2}$ & $72^{2}$ & $\overline{40^{2}}$ \\
\hline Time in Unstructured Play Activities & $\underline{68^{2}}$ & $-\overline{17}^{2}$ & $-22^{2}$ & $71^{2}$ & $-\overline{22^{2}}$ & $-\overline{12^{2}}$ & $38^{2}$ \\
\hline Importance of Play & $\overline{75^{2}}$ & $36^{2}$ & $41^{2}$ & $\overline{44}^{2}$ & $26^{2}$ & $67^{2}$ & $\underline{51^{2}}$ \\
\hline Importance of Structured Play & $\overline{48^{2}}$ & $59^{2}$ & $58^{2}$ & $09^{1}$ & $44^{2}$ & $\underline{83}^{2}$ & $\overline{51}^{2}$ \\
\hline Importance of Unstructured Play & $72^{2}$ & $21^{2}$ & $-26^{2}$ & $79^{2}$ & $19^{2}$ & $-26^{2}$ & $49^{2}$ \\
\hline Authoritarian Parenting Style & $-\overline{58}^{2}$ & $\underline{79^{2}}$ & $\underline{70}^{2}$ & $-\overline{45^{2}}$ & $\underline{66}^{2}$ & $39^{2}$ & $-73^{2}$ \\
\hline Authoritative Parenting Style & $74^{2}$ & $-\overline{49}^{2}$ & $-\overline{38}^{2}$ & $\underline{69^{2}}$ & $-\overline{71^{2}}$ & $-28^{2}$ & $\overline{74^{2}}$ \\
\hline Sex Bias Scale & $-\overline{57}^{2}$ & $\overline{44^{2}}$ & $\overline{38^{2}}$ & $-\overline{26^{2}}$ & $\overline{74^{2}}$ & $42^{2}$ & $-\overline{41}^{2}$ \\
\hline Positive Affect & 05 & -04 & -02 & 04 & -01 & 03 & 04 \\
\hline Negative Affect & -04 & 01 & 00 & -03 & 02 & -01 & -04 \\
\hline Depression & -03 & -01 & -00 & -04 & -01 & -02 & -05 \\
\hline Child's Nonverbal Intelligence & 05 & -02 & -01 & 07 & -01 & 03 & 05 \\
\hline Child's Academic Achievement & 02 & 00 & -01 & 03 & 02 & 05 & 06 \\
\hline
\end{tabular}

Note. Imagin $=$ Imaginative Play, Gender $=$ Gender Typing, Imprtnc $=$ Importance

${ }^{1} p<.01$

${ }^{2} p<.001$ 
The Play Freedom factor was found to correlate positively with the total number $(\mathrm{r}=.69, p<.001)$ and time spent $(\mathrm{r}$ $=.72, p<.001)$ in play activities in which their children engaged, particularly strongly for unstructured $(\mathrm{r}=.66$, $p<.001)$ more so than for structured $(\mathrm{r}=.31, p<.001)$ activities. Mothers who were high in allowing their children freedom to play as they wished regarded play as important in children's development $(r=.75, p<.001)$, particularly unstructured play $(\mathrm{r}=.72)$ but also structured play programs $(\mathrm{r}=.48, p<.001)$. Children whose play was more self-determined were shown to have mothers whose parenting style was authoritative $(\mathrm{r}=.74, p<.001)$ rather than authoritarian $(\mathrm{r}=-.58, p<.001)$. The more that mothers believed in gender appropriate play materials and activity choices, the less autonomy they allowed their children to make choices about their play $(\mathrm{r}=-.57, p<.001)$. The freedom that mothers allowed their children in play was unrelated to their positive $(r=.05, p>.05)$ or negative affect $(r=-.04, p>.05)$ or level of depression $(r=-.03, p>.05)$, or to children's academic performance $(r=.02, p>.05)$ and nonverbal intelligence $(r=.05, p>.05)$.

The second factor comprising mothers' perceptions of their children's play was Maternal Rules, with higher scores referring to a greater number of rules governing how, when, where, and with whom children could play. A negative correlation was found between the number of play activities and maternal rules $(r=-.22, p<.001)$, while time spent playing was found to be positively correlated $(r=.25$, $p<.001)$. These findings indicated that children with mothers who imposed a lot of rules on their play tended to participate in fewer different play activities but spent time on the ones in which they did play. Mothers with a larger number of rules governing their children's play enrolled their children in structured play activities and minimized children's participation in unstructured play. While even mothers with many rules for play regarded play to be important for their children $(r=.36, p<.001)$, they tended to deem structured play $(r=.59, p<.001)$ as more valuable than unstructured play $(r=.21, p<.001)$. Consistent with the literature on parenting style, authoritarian mothers had a larger number of play rules $(r=.79, p<.001)$ while authoritative mothers had fewer $(r=-.49, p<.001)$. Mothers with rules for their children's play also scored higher on the Sex Bias scale $(r$ $=.44, p<.001)$, and it is likely that their preference for structured play activities arose from their many play rules, including conformity to what they considered to be gender appropriate. The extent to which mothers imposed rules upon their children for play was unrelated to children's academic achievement in math or reading $(r=.00, p>.05)$ or to their nonverbal intelligence $(r=-.02, p>.05)$ and was independent of mothers' depression $(r=-.01, p>.05)$, positive $(r=-.04, p>.05)$ or negative affect $(r=.01, p>.05)$.

Mothers' concerns for the safety of their children while playing comprised the third factor. Correlations revealed that as mothers' worries increased, the number $(r=.58, p<.001)$, time $(r=.69, p<.001)$, and importance $(r=.58$, $p<.001$ attributed to children's structured play also increased, while these measures decreased for unstructured play $(r=-.17, p<.001 ; r=-.22, p<.001 ; r=-.26, p<.001$, respectively). This would suggest that mothers who have worries about their child's safety during play feel more reassured with structured play activities that are organized, supervised, and typically led by adults. Authoritarian mothers were much more likely to report safety concerns for their playing children $(r=.70, p<.001)$, while the opposite was found for authoritative mothers $(r=-.38, p<.001)$. Mothers who had safety concerns about their children's play were also more likely to direct their children into play activities that they considered to be gender appropriate $(r$ $=.38, p<.001)$. Mothers' safety concerns about their children when playing were unrelated to their positive $(r=-.02$, $p>.05)$ or negative $(r=.00, p>.05)$ affect, depression $(r=$ $-.00, p>.05)$, or their child's academic achievement $(r=-.01$, $p>.05)$ or nonverbal intelligence $(r=-.01, p>.05)$.

A significant aspect comprising how mothers perceived their children's play related to the degree of imagination that was incorporated into play. Mothers who viewed imaginative play favorably viewed play as important for their child $(r=.44, p<.001)$, and their children were more likely to spend time in unstructured $(r=.71, p<.001)$ versus structured $(r=-.23, p<.001)$ play activities. The more authoritative the mother was in her parenting style, the greater the likelihood that she reinforced the appearance of imagination in her children's play $(r=.69, p<.001)$, while the opposite was the case for authoritarian mothers $(r=-.45$, $p<.001)$. Gender stereotyping was found to be negatively related to appreciation of imaginative play $(r=-.26, p<.001)$ - mothers who endorsed imagination in their children's play were less likely to steer their children into what they regarded as gender appropriate play activities. The extent to which mothers were supportive and encouraging of children's imaginative play was unrelated to their degree of depression $(r=-.04, p>.05)$, positive $(r=.04, p>.05)$ or negative $(r=-.03, p>.05)$ affect, or their children's nonverbal intelligence $(r=.07, p>.05)$ or academic achievement $(r=.03, p>.05)$.

Mothers' belief that there are distinct play activities for boys and girls related strongly to their child's participation in structured play activities, in terms of the time they spent $(r$ $=.56, p<.001)$, the number of such activities in which they were involved $(r=.47, p<.001)$, and the importance the mother attributed to them $(r=.44, p<.001)$.Not surprisingly, mothers' view that children's play should be gender appropriate was more strongly held by authoritarian $(r=.66$, $p<.001)$ than by authoritative $(r=-.71, p<.001)$ mothers. Mothers' beliefs about gender typing their children's play activities related strongly to their general sex bias in parenting $(r=.74, p<.001)$. The tendency to gender stereotype their children in their play did not relate to the mother's positive $(r=-.01, p>.05)$ or negative $(r=.02$, $p>.05)$ affect, depression $(r=-.01, p>.05)$, or to the child's academic performance $(r=.02, p>.05)$ or nonverbal intelligence $(r=-.01, p>.05)$.

The importance that mothers attributed to children's 
participation in out-of-school structured play activities was evidenced by the number $(r=.81, p<.001)$ and time $(r=.72$, $p<.001)$ their child spent in structured play programs, as well as by the importance ratings assigned to such types of play $(r$ $=.83, p<.001)$. The negative correlations with unstructured play (number: $r=.09, p<.01$; time: $r=-.12, p<.001$; importance: $r=.26, p<.001$ ) suggested that mothers perceived structured play activities and free play to be qualitatively very different, as their high regard for out-of-school structured play activities did not extend into perceiving there to be strong merit to children's free play. The more authoritative the mother, the less likely she was to view out-of-school structured play activities as important for her child $(r=-.28, p<.001)$, while more authoritarian mothers did see them as having some value $(r=.39, p<.001)$. It was not surprising to find that mothers who felt out-of-school structured play activities were important also tended to have specific beliefs about play being gender appropriate $(r=.42, p<.001)$. The importance that mothers attributed to their child's participation in out-of-school structured play activities was unrelated to the child's nonverbal intelligence $(r=.03, p>.05)$ or academic performance $(r=.05, p>.05)$ or to the mother's level of depression $(r=-.02, p>.05)$ or positive $(r=.03, p>.05)$ or negative $(r=-.01, p>.05)$ affect.

The final factor on the MPCP Scale addressed mothers' beliefs that their children should be involved in choosing the out-of-school structured play activities in which they participated. Mothers who felt that children should be given such choice rated these activities as important $(r=.51$, $p<.001)$, and their children were involved in a greater number of different play activities $(r=.66, p<.001)$ and devoted a greater commitment of time to them $(r=.61$, $p<.001)$. The sentiment that children should be given significant input in their out-of-school structured play related strongly to parenting style - with authoritarian mothers $(r=$ $-.73, p<.001$ ) believing their children should be significantly less involved in selecting activities than authoritative mothers $(r=.74, p<.001)$. The conviction that children should be consulted about their out-of-school structured activity participation was more likely to be characteristic of mothers who weren't concerned with gender stereotypes ( $r=$ $-.41, p<.001)$. As with all previous factors, mothers' depression $(r=-.05, p>.05)$, positive $(r=.04, p>.05)$ or negative $(r=-.04, p>.05)$ affect, and children's academic achievement $(r=.06, p>.05)$ and nonverbal intelligence $(r$ $=.05, p>.05)$ were unrelated to mothers' feelings that children should be involved in decisions about their out-of-school structured play activities.

\subsubsection{Convergent and Discriminant Validity}

3.5.2.1 Reliability and Validity Testing of the Children's Perceptions of Their Mother's Beliefs and Practices About Their Play: Heteromethod Correlations

As a preliminary step to examining convergent and discriminant validity, it was necessary to show that the children's scale (CPMBP) we constructed was comparable to the mothers' version (MPCP) and could be used to test the convergent and discriminant validity of the MCPC Scale factors. Thus, principal-axis factor analysis (PAF) with oblique rotation was conducted on the 30 items comprising the CPMBP (children's) scale, and seven factors were extracted that met accepted criteria [72]. The factors exactly corresponded to those that emerged from the MPCP data and confirmed that we had written items for children that presented a close match to the item content of the MPCP. Each of the factors was also shown to have acceptable internal consistency (range of .81 to .89 ) and none of the items loaded highly (above .30)[26] on more than one factor. The items, factor loadings, eigenvalues, unique and cumulative factor variances, and internal consistency alpha coefficients for the children's version (CPMBP) of the MPCP are shown in Table 3.

To examine the hierarchical arrangement of the subscales derived from the children's ratings, we again subjected this data to PAFs with oblique rotation. Results resembled the factor structure found for mothers' ratings - the CPMBP data was characterized by two large higher order factors which together accounted for $77.42 \%$ of the variance. After the rotation, the first factor clearly reflected a Maternal Permissiveness in "Unstructured (Free) Play" dimension with the five subscales loading .40 or better on this factor: Play Freedom (.78), Maternal Rules (-.69), Play Safety (-.63), Imaginative Play (.51), Gender Typing (-.79). The second factor could be identified as a higher order Out-of-School Structured Play dimension - it was defined by Importance (.62) and Child's Choice (.71), together accounting for $64.80 \%$ of the variance. Thus, the two sets of ratings yielded congruent solutions, both producing higher order Unstructured Play and Out-of-School Structured Playsubscales that exactly paralleled the MPCP based on mothers' data. Confirmatory factor analysis on the children's data replicated the findings reported earlier for mothers' data: the two-factor solution (Model 3, see Figure 1) was found to present the best fit, $2=2.16, \mathrm{CFI}=.91, \mathrm{RMSEA}=.02$. All of the other models shown in Figure 1 were tested and best-fit indices were substantially poorer than those for Model 3. These findings confirmed that we could utilize the children's scores on the CPMBP and its factors as one of the measures against which to test the construct validity of the MPCP Scale. 
Table 3. Results of Factor Analysis and Reliability Tests for Children's Perceptions of Their Mother's Beliefs and Practices About Their PlayScale Items

FREE PLAY

\begin{tabular}{|c|c|c|c|c|c|c|c|}
\hline Item & $\begin{array}{l}\text { "Play "I " } \\
\text { Freedom" } \\
\text { I. }\end{array}$ & $\begin{array}{l}\text { "Matemal } \\
\text { Rules" } \\
\text { II. }\end{array}$ & $\begin{array}{l}\text { "Play " } \\
\text { "Safety" } \\
\text { III. }\end{array}$ & $\begin{array}{c}\text { "Imaginative } \\
\text { "Play" } \\
\text { IV. }\end{array}$ & $\begin{array}{l}\text { "Gender } \\
\text { Typing" } \\
\text { V. }\end{array}$ & $\begin{array}{l}\text { "Importance" } \\
\text { VI. }\end{array}$ & $\begin{array}{l}\text { "Child's } \\
\text { "Choice" } \\
\text { VII. }\end{array}$ \\
\hline My mom lets me decide how I want to play. & .8101 & -.2899 & -.2047 & .2489 & -.1861 & -.0788 & .2380 \\
\hline 2. My mom lets me decide who I want to play with. & .7226 & -.2241 & -.1688 & .1421 & -.2820 & -.1172 & .2067 \\
\hline $\begin{array}{l}\text { 3. My mom lets me decide if I want to share my } \\
\text { toys with other kids or not. }\end{array}$ & .6140 & -.1928 & .1002 & .0899 & .0079 & .0047 & .1784 \\
\hline $\begin{array}{l}\text { 4. My mom lets me decide where I want to play in } \\
\text { my house. }\end{array}$ & .6042 & -.2045 & -.1967 & .2974 & -.0781 & -1049 & -.0038 \\
\hline 5. My mom lets me decide when I want to watch TV. & .5948 & -.4288 & -.1281 & .0577 & -.1984 & -.2641 & -.0998 \\
\hline 5. My mom lets me decide how to play with my toys. & .7455 & -.0601 & -.2207 & .1349 & -.1882 & .0144 & .1813 \\
\hline $\begin{array}{l}\text { 7. If I do something my mom thinks is wrong I know } \\
\text { I'll get punished. }\end{array}$ & -.2847 & .6872 & .2871 & -.0788 & .1642 & .1127 & -.0078 \\
\hline 8. My mom has a lot of rules for my play. & -.2991 & .8890 & .2955 & -.1140 & .2799 & .2243 & -.1377 \\
\hline $\begin{array}{l}\text { 9. My mom reminds me a lot about her rules for how } \\
\text { I should play. }\end{array}$ & -.2986 & .6597 & .2469 & -.0377 & .1493 & .1176 & -.0154 \\
\hline $\begin{array}{l}\text { 10. When I play a game with my mom she makes me } \\
\text { follow all the rules. }\end{array}$ & -.1899 & .7225 & .1304 & -.2087 & .1876 & .2049 & -.0762 \\
\hline $\begin{array}{l}\text { 11. My mom only lets me play in certain rooms in } \\
\text { my house. }\end{array}$ & -.2240 & .6851 & .3307 & .1728 & .2147 & .1725 & -.0879 \\
\hline $\begin{array}{l}\text { 12. My mom doesn't let me leave my toys around } \\
\text { my house. }\end{array}$ & -.2641 & .7767 & .2814 & .0995 & .1563 & .1439 & .0621 \\
\hline $\begin{array}{l}\text { 13. When I go outside to play someone older has } \\
\text { to go with me. }\end{array}$ & -.2770 & .2044 & .8611 & .1078 & -.2176 & -.1876 & -.1547 \\
\hline $\begin{array}{l}\text { 14. My mom won't let me go to a nearby play area } \\
\text { withoutsomeone to watch me. }\end{array}$ & -.1983 & .2044 & .8611 & .1078 & -.2176 & -.1876 & -.1547 \\
\hline 15. My mom won't let me run around when I'm & -.2054 & .2016 & .8094 & .0801 & .1679 & .2217 & -.0025 \\
\hline
\end{tabular}

STRUCTURED PLAY 
16. My mom likes when I make up my own games to play.

17. My mom wouldnot be mad if I told her I made up an imaginary friend to play with.

18. My mom doesn't get mad if I get dirty when I'm playing.

19. My mom doesn't get upset if I make a mess when I'm playing.

20. If I'm a girl, my mom would get mad if I played with boys'toys.

21. If I'm a boy, my mom would get mad if I played
with girls' toys.

22. If I'm a girl, my mom would get upset with me if she saw me playing a boy'sgame.

23. If I'm a boy, my mom would get upset with me if she saw me playing a girl'sgame.

24. My mom thinks it's important I do activities after school.

25. My mom thinks it's good for me to be doing activity programs when I'm not in school.

26. My mom likes me to be busy when I'm not in school.

27. My mom lets me decide if I want to do an after school activity or not.

28. If my mom knows about an after school activity, she will ask me if I want to do it or not.

29. If I'm doing an after school activity and I don't like it, my mom will let me stop doing it.

30. If there was an after school activity I wanted to do, I could tell my mom and she would probably

$\begin{array}{lllllll}.2880 & -.1337 & -.0083 & . \mathbf{8 1 1 4} & -.1562 & -.0734 & .2287 \\ .2679 & -.0794 & .0106 & . \mathbf{8 0 7 9} & -.0984 & -.0089 & .1278 \\ .1842 & -.2241 & -.2077 & .7460 & -.0822 & -.1832 & -.0027 \\ .1644 & -.2087 & -.1876 & .6844 & -.1003 & -.1499 & .0091 \\ -.2899 & .2107 & .1175 & -.1229 & .7961 & .0865 & -.2449 \\ -.2976 & .2894 & .1378 & -.1645 & . \mathbf{8 7 2 2} & .1847 & -.2278 \\ -.2101 & .2076 & .0884 & -.1387 & .7634 & .1254 & -.2575 \\ -.2658 & .2899 & .1680 & -.1719 & .8559 & .1738 & -.1863 \\ -.2778 & .1799 & .2189 & -.2122 & .1991 & .8312 & .1178 \\ . .2439 & .1862 & .2004 & -.2309 & .2148 & .8029 & .1344 \\ .1142 & .2044 & .1395 & -.1996 & .1365 & .7041 & .1097 \\ .2877 & -.2498 & -.1849 & .1767 & -.1988 & .1994 & . \mathbf{8 6 4 1} \\ .2163 & -.2667 & .1216 & .2049 & .1897 & .2078 & . \mathbf{8 2 3 0} \\ .2044 & -.2961 & .0079 & .1107 & .0774 & -.2239 & .7463 \\ .230 & -.2210 & .1427 & .1866 & -.1362 & .2491 & . \mathbf{8 7 0 5}\end{array}$
let me try it. 
within Free Play and Structured Play Subscales:

\begin{tabular}{lccccc|cc} 
Eigenvalue & 3.8447 & 3.3910 & 2.7882 & 2.3894 & 1.9967 & 3.2469 & 2.6813 \\
Unique explained variance (\%) & 24.82 & 20.34 & 14.12 & 11.60 & 8.32 & 36.91 & 27.89 \\
Cumulative explained variance (\%) & 24.82 & 45.16 & 59.28 & 70.88 & 79.20 & 36.91 & 64.80 \\
Internal Consistency (Alpha Coefficient) & .8649 & .8550 & .8516 & .8328 & .8899 & .8103 & .8541 \\
\hline
\end{tabular}

Table 4. Intercorrelations (decimals omitted) Among Subscales Based on Mothers' (MPCP) and Children’s(CPMBP) Ratings

Children's Ratings

\begin{tabular}{lccccccc}
\cline { 2 - 7 } Mothers' Ratings & 1 & 2 & 3 & 4 & 5 & 6 & 7 \\
\hline 1. Play Freedom & $\mathbf{8 7 ^ { 2 }}$ & $-46^{2}$ & $-43^{2}$ & $59^{2}$ & $-52^{2}$ & $-29^{2}$ & $50^{2}$ \\
2. Matemal Rules & $-51^{2}$ & $\mathbf{8 8 ^ { 2 }}$ & $66^{2}$ & -38 & $55^{2}$ & $33^{2}$ & $-29^{2}$ \\
3. Play Safety & $-48^{2}$ & $72^{2}$ & $\mathbf{7 9 ^ { 2 }}$ & $-41^{2}$ & $38^{2}$ & $32^{2}$ & $-31^{2}$ \\
4. Imaginative Play & $49^{2}$ & $-41^{2}$ & $-39^{2}$ & $\mathbf{8 3 ^ { 2 }}$ & $-29^{2}$ & $-28^{2}$ & $29^{2}$ \\
5. Gender Typing & $-61^{2}$ & $64^{2}$ & $41^{2}$ & $-39^{2}$ & $\mathbf{8 7 ^ { 2 }}$ & 32 & $-33^{2}$ \\
6. OSSP Importance & $-33^{2}$ & $32^{2}$ & $40^{2}$ & $-29^{2}$ & $41^{2}$ & $\mathbf{8 1 ^ { 2 }}$ & $-36^{2}$ \\
7. OSSP Child's Choice & $46^{2}$ & $-28^{2}$ & $-36^{2}$ & $34^{2}$ & $-39^{2}$ & $-32^{2}$ & $\mathbf{8 9 ^ { 2 }}$ \\
\hline
\end{tabular}

Note. OSSP $=$ Out-of-school Structured Play, MPCP = Mothers' Perceptions of Their Children's Play Scale, CPMBP = Children's Perceptions of Their Mother's Beliefs and Practices About Their Play Scale Mothers' MPCP scores are below the diagonal; children's CPMBP scores are above the diagonal, bold-face correlations on the diagonal represent relationships between children's and mothers' ratings on each subscale.

${ }^{1} p<.01$

${ }^{2} p<.001$ 


\subsubsection{Further Validity Testing: Monomethod Correlations}

To continue this phase of the validity testing, it was instructive to first examine the associations among the seven factors separately for each of the two types of raters: mothers and their children. These correlations are presented in Table 4 where scale intercorrelations for mothers' ratings on each factor are shown below the diagonal and children's ratings are displayed above the diagonal. First, it is important to note that the mothers' and children's ratings on each factor are very similar. Second, for both sets of ratings, a comparison indicates that these subscales are significantly interrelated, reflecting the influence of general, higher order dimensions and thus providing support for the presence of the hierarchical model. With regard to both sets of ratings, every subscale is significantly related to one or more of the others. However, the two subscales relating to out-of-school structured play ("Importance", "Child's Choice") generally have low to moderate correlations with the other subscales, suggesting that they possess a greater degree of specificity, addressing a specific type of play -structured out-of-school play activities. In contrast, the remaining subscales clearly reflect the influence of another dimension that we might consider to be maternal permissiveness in unstructured (free)play - the degree to which mothers believe they should not impose guidelines and restrictions on their children's play. These five subscales are strongly correlated, with coefficients ranging from -.28 to .72 for mothers' ratings and -.28 to .66 for children's assessments. It is clear from the signs of the correlations that the Play Freedom and Imaginative Play subscales represent the antithesis of the other three subscales (Maternal Rules, Play Safety, Gender Typing), yet their higher negative correlations with all three suggest the single higher order "Maternal Permissiveness" factor. Play Freedom and Imaginative Play reflect mothers' permissiveness and leniency about their children's play, while Maternal Rules, Play Safety, and Gender Typing reflect their imposition of restrictions and boundaries to govern their children's play.

The correlations along the diagonal of Table 4 all reveal highly significant positive relationships between the ratings of the mothers and those of the children on each factor (ranging from .79 to .89). This allows us to conclude that the convergent validity of the MPCP Scale is high and further suggests that mothers communicated clearly to their children what their beliefs were about play and how they would be put into practice with the provision (or not) of rules about partners, locations, and content of play.

To further examine relationships between mothers' and children's data, we also compared the means of the subscales. This was done in light of the common criticism that self-report data is biased and that it is important to consider non-self-report data as well when attempting to establish the validity of a test of a psychological construct [73-74]. Given this concern, it would be predicted that self-raters (the mothers) would respond in a more socially desirable way (i.e., higher levels of permissiveness and lower levels of restrictions) than would the children rating their mothers' play communications and practices. Table 5 presents the means and standard deviations for the seven subscales and the two sets of ratings on each, as well as the t-values to determine whether or not there were differences between them. The lack of a significant difference between mothers' and children's ratings on any of the subscales is inconsistent with the view of self-ratings as globally vulnerable to defensive, socially desirable responding. Rather, this suggests that the mothers in the study were in touch with and honestly reporting their feelings about their children's play, and that they had clearly communicated and implemented them into practice such that children were well aware of them.

Table 5. Standardized Means, Standard Deviations, and t-tests for Mother and Child Ratings on MPCP Factors

\begin{tabular}{|c|c|c|c|c|c|}
\hline \multirow[b]{2}{*}{ Subscale } & \multicolumn{2}{|c|}{ Mother Ratings } & \multicolumn{2}{|c|}{ Child Ratings } & \multirow[b]{2}{*}{$t(696)$} \\
\hline & $\mathrm{M}$ & $\mathrm{SD}$ & $\mathrm{M}$ & $\mathrm{SD}$ & \\
\hline Play Freedom & 4.02 & 1.22 & 3.06 & .87 & .89 \\
\hline Matemal Rules & 3.31 & 1.49 & 2.18 & 1.02 & 1.18 \\
\hline Play Safety & 3.19 & .98 & 1.99 & .81 & 1.46 \\
\hline Imaginative Play & 3.26 & 1.67 & 2.47 & 1.33 & 1.77 \\
\hline Gender Typing & 2.91 & 2.04 & 3.11 & .65 & .79 \\
\hline OSSP Importance & 3.77 & 1.77 & 2.83 & 1.12 & 1.91 \\
\hline OSSP Child's Choice & 2.20 & 2.16 & 1.62 & 1.30 & 1.06 \\
\hline
\end{tabular}

Note. Mothers' ratings based on 6-point scale and Children's ratings based on 4-point scale were both separately converted to $\mathrm{z}$-scores to conduct t-test. Means and standard deviations presented are based on raw scores.OSSP $=$ Out-of-school Structured Play ${ }^{1} p<.01 \quad{ }^{2} p<.001$ 


\subsection{Testing for Gender and Age Differences}

With a wealth of descriptive studies [1-2] demonstrating that boys and girls have different play preferences and styles in this developmental stage, we thought it likely that the reason for these differences might lie in how mothers viewed the play of sons and daughters and distinctly reinforced their play choices and behaviors[75-77]. In addition, the absence of literature exploring age differences in play within this developmental period suggested that it would be advantageous to determine if mothers viewed play differently for third, fourth, or fifth grade children. We thus conducted a Sex x Grade $(2 \times 3)$ multivariate analysis of variance (MANOVA) with the seven factor scores serving as dependent variables. Results of the MANOVA yielded a nonsignificant main effect for both sex $(F(1,695)=1.72$, $p>.05)$ and Grade $(F(2,692)=.91, p>.05)$, as well as for their interaction $(F(2,690)=1.04, p>.05)$, indicating no differences between boys or girls, or between the ages represented in the sample, in terms of how their mothers viewed play.

\section{Discussion}

The goal of the current study was to develop a self-report measure of how mothers perceive their elementary school-aged children's play. After pilot testing items resulting from focus groups of mothers reflecting on their feelings, beliefs, and issues concerning their children's play, we developed 37 items for further scrutiny. An expert panel consisting of researchers in child development, teachers of children in third through fifth grades, and assistant principals suggested minor modifications and attested to the face and content validity of the revised 36-item version, which we named the Mothers' Perceptions of Their Children's Play (MPCP) Scale.

Analyses revealed that the MPCP Scale had a hierarchical structure consisting of two higher-order factors: Out-of-School Unstructured (Free) Play and Structured Play. In contrast to mothers' perceptions of play for younger-aged children as the dichotomy between play as beneficial to the child's development versus the view that it is distracting from more important activities such as academic preparation[17,19], mothers of older elementary school-aged children did not view play in the same way. Instead, they made a clear distinction between unstructured (free) play and structured play activities and programs, and the overarching theme for each of these types of play was the degree to which mothers desired to place restrictions and boundaries on their children's play. The developmental progression in children's play that has been well-documented illustrating physical, cognitive, social, and emotional advancements from pre- to school age years [1,2]was reflected in the different ways in which mothers think about their children's play as the children mature. As children's play becomes more complex, coordinated, integrated, and socialized, it was not surprising to find that mothers' issues about their children's play changed. Children's increasing desire to socialize with peers and the increasing importance placed on social conformity and membership in cliques, particularly for the children in the older age groups[78], presents mothers with a dilemma regarding the extent to which they should place rules and restrictions on their children's play. Added to these natural developmental changes is the increasing public awareness of the dangers of children playing unsupervised or being negatively influenced by playmates who might seek fun in deviant ways. The increasing realization among mothers that one way to allay these apprehensions is to enroll their children in adult-supervised structured recreation programs is evidenced by the finding that structured play programs emerged as a higher-order factor when mothers thought about their children's play. The large amount of variance accounted for by the total scale score $(80.71 \%)$, as well as independently by each of the two subscales $(81.52 \%$ for Unstructured Play and $79.26 \%$ for Structured Play) indicated that we had indeed captured the ways in which mothers think about their children's play at this age, and that the subscales could each be utilized separately.

The confirmatory factor analysis revealed that this two-dimension solution was the best fit to the data, and that there were five factors, equivalent in their weighted contribution, that comprised the Unstructured Play dimension and an additional two comparable ones that made up the Structured Play dimension. For the Unstructured (Free) Play subscale, the Play Freedom and Imaginative Play factors assessed the extent to which mothers allowed their children the freedom to make their own choices and to express their creativity and imaginative in their play. In contrast, the Maternal Rules, Play Safety, and Gender Typing factors in the Free Play subscale reflected the degree to which mothers instituted rules for their children's play, including where play could occur, with whom children could play, how they could play, and the selection of gender appropriate materials and activities. Our analyses also indicated that, although significantly correlated, the high internal consistency coefficients and test-retest stability shown for each factor provided strong evidence that each of the factors presented a unique contribution to the higher-order Unstructured (Free) Play dimension. A total score for the Unstructured Play subscale would entail reverse coding for the latter three factors (except where noted in Table 1), so that they were consistent with the scoring on the Play Freedom and Imaginative Play factors.

For the Structured Play dimension, mothers viewed their children's involvement in two ways: by the importance they attributed participating in these activities to their child's development, and by the extent to which they permitted their child to have a voice in decisions regarding their involvement in these types of activities. Higher scores on each of these factors indicated that mothers felt structured play activities were important for their children and that children should have a significant voice in what activities were chosen and how long participation continued, 
respectively. The analyses revealed that mothers' feelings about their children's engagement in structured activities were not as strong as their sentiments about unstructured play, although it is likely that the lack of specific mention of unstructured (free) play in many of the items loading highly on the first subscale included thoughts about more formal structured play activities as well. Although the correlations were generally not as high (but were all statistically significant) in the Structured Play dimension as in the Unstructured Play dimension, the large percentage of variance that was accounted for by these two component factors, and the high internal consistency and temporal stability of the factors, allowed us to conclude that this dimension adequately represented mothers' sentiments about their children's structured play activities.

Evidence for the concurrent validity of the dimensions and their underlying factors was shown by the relationships that were obtained with the criterion measures. Virtually all of the measures chosen to test the concurrent validity of the instrument were highly significant $(\mathrm{p}<.001$; only two were significant at the .01 level, and none below that), however, the measures assessing time and importance of structured play correlated higher with the structured play dimension, and the reverse was obtained for unstructured play. In addition, mothers who possessed a more authoritarian parenting style were shown to be more restrictive and have more rules for their children when playing, and to believe that children should have minimal input in selecting their play companions and activities. These same findings were evinced for mothers who held strongly to traditional sex-role stereotypes in play and more generally - they imposed more conditions on play and were more likely to endorse structured (adult-controlled and mother-determined) rather than unstructured (free) play. The emergence of a factor focusing on gender stereotyping in mothers' thoughts about their children's play is consistent with Eccles' model $[14,79-80]$ that lays importance on this construct in achievement motivation and extracurricular activity participation for older youth and adolescents. The nonsignificant relationships between any of the opinions held by mothers about their child's structured or unstructured play did not relate to the child's nonverbal or academic abilities, nor did they relate to the mother's affect (positive or negative) or evidence of depression. The latter findings provided consistent and strong evidence for the discriminant validity of the scale.

In addition, we found compelling support for the contention that not only did mothers hold certain beliefs and opinions about play, and that they communicated them clearly to their children. When we designed an instrument (demonstrating excellent psychometric properties) with items to address each of the factors that had emerged on the scale for mothers, the correlations between mothers' scores and those of their children on every factor were highly positive and significant. This provided a test of the convergent validity of our scale, and also indicated that the mothers in our study had unequivocably conveyed their views to their children about both structured and unstructured play. This finding is consistent with previous research conducted on older youth and adolescents that demonstrated that mothers provide clear directionsto their children about their extracurricular activities[12,14-15]. Expressing and reinforcing their viewpoints about play to their children is one aspect of how mothers socialize their children. Mothers' beliefs about play influence how they interact with their children and what behaviors they reward or extinguish, which in turn influences the child's developmental outcomes. Their beliefs about play influence how they organize their children's out-of-school lives, from the ways in which children spend their time, to the objects found in their home environment (toys and other materials available for play), to the social interactions they have with peers and others [9-10,15-16]. Therefore, it is of vital importance to understand how mothers, who have primary responsibility for organizing their child's play life, think about play and the priorities they ascribe to its various aspects. The Mothers' Perceptions on Their Children's Play Scale makes a significant contribution in the absence of any measures assessing this construct for children of middle elementary school age[6]. It is likely that children whose mothers differ on either or both of the Structured or Unstructured Play dimensions will take on different trajectories as a result of how their mothers channel their play, which could result in differential benefits and consequences at that age and in later years. For example, studies have shown that extracurricular play activities influence youth and adolescent identity formation [47,81], psychosocial adjustment [42,82-85], self-efficacy [86-87], and academic performance $[52,81,88-89]$, and reduce problem behaviors as well $[43,47,75,90-94]$. However, very little of this research has been conducted with children younger than middle school age, and the few studies that have been conducted have examined outcomes as a function of rates of participation in structured play. Therefore, it is crucial to fill this gap in our depth of understanding how children might realize the benefits or consequences of their play activities by examining how their mothers socialize them children in their play through their early years. The Mothers Perceptions of Their Children's Play Scale is intended to provide an important first step in investigating this socialization process by providing a tool that has been shown to comprehensively and adequately capture how mothers perceive their children's play and the practices that arise from their perceptions.

Finally, it was notable that no age or gender differences were found in how mothers viewed structured or unstructured play. While there is a wealth of literature that chronicles the different play preferences, styles, activities, and peer interactions between boys and girls in this age range $[1,2]$, it was apparent from this data that mothers think about the same issues when they think about their children's play. They have equivalent views about how much freedom should be allowed in play and the extent to which there should be rules governing play choices, content, and location. 
They also tend to worry to the same degree about the safety of their child at play, and to be as likely to gender stereotype the play activities of sons and daughters. In addition, mothers appeared not to differentiate the importance of structured play activities based on the child's gender, whether they felt that such programs were worthwhile or not. This finding provides a significant contribution to the literature in that the gender differences that are so pervasively reported are now shown to be restricted to what play looks like, or to the child's, teacher's, or observers' interpretations, rather than to those of the mother. Finally, the lack of an age main effect or interaction was likely due to the narrow range represented by the children in the sample. This is an important outcome in and of itself, in that there is a dearth of empirical studies that investigate play by considering the individual years that fall within the middle and late childhood developmental stages.

\subsection{Limitations and Future Directions}

The attributes of the parents who participated in the study show that they are above the national median for both household income and educational status, and the vast majority was of European-American descent. A wealth of studies have consistently shown that mothers of different cultural backgrounds [18,95-96] and socioeconomic living conditions [52,93,97-99] place varying degrees of importance on their children's free play and involvement in structured play programs. Thus, future studies should be conducted to compare these findings and the generalizability of the MPCP instrument for use with subcultures with more diverse characteristics.

\section{Conclusion}

Perhaps it is because of the more unpredictable and seemingly violent times in which we now find ourselves, in contrast to preceding generations, but the perspectives of mothers about their children's play seems to have as its core the safety of the child. That this appears to be more prominent in their minds and translates to the imposition of rules about behaviors and boundaries, as well as cautions and conversations about play activities, the factors that have emerged as constituting the perspectives of the mothers about their child's play in the present study bear witness to this theme. Since research on children's play at their age has almost universally relied on the reports of mothers and other adults (teachers, coaches, graduate student observers) who may have the same priorities when viewing a playing child, it is important to keep this bias in mind for empirical studies that include play as a salient variable.

Alternatively, the play of children of middle to late childhood and beyond can and should be assessed through the eyes, voices, and intentions of the children themselves, as recent research has shown that their perspectives differ markedly from that of parents or other adults $[6,60]$. The MPCP instrument is an important contribution to the literature assessing the trajectory that children's play takes on as a result of earlier mother influences, and a crucial question for future research concerns the developmental outcomes that might result from differing degrees of confluence between mother and child. These findings are important for demonstrating that children and their mothers do not think about their play in the same way, and the implications of this await further in-depth research.

\section{REFERENCES}

[1] F. P. Hughes. Children, Play, and Development, 4th ed., Sage, Thousand Oaks CA, 2010.

[2] J. E. Johnson, J. F. Christie, F. Wardle. Play, Development, and Early Education, Allyn and Bacon, Boston, 2005.

[3] J. Howard. Eliciting young children's perceptions of work and learning using the Activity Apperception Story procedures, Early Child Development and Care, 172, 489-502, 2002.

[4] K. H. Rubin, G. Fein, B. Vandenberg. Play. In E. Hetherington (Ed.), Handbook of Child Psychology: Vol. 4: Socialization, Personality, and Social Development(pp. 693-774), Wiley, New York, 1983.

[5] B. Sutton-Smith. The Ambiguity of Play,Harvard University Press, Cambridge, MA, 1997.

[6] K. R. Fisher, K. Hirsh-Pasek, R. Golinkoff, S. Gryfe. Conceptual split? Parents' and experts' perceptions of play in the 21st century,Journal of Applied Developmental Psychology, Vol. 29, 305-316, 2008.

[7] L. Rothlein, A. Brett. Children's, teachers and parents perceptions of play, Early Childhood Research Quarterly, Vol. 2, No. 1, 45-53, 1987.

[8] Y. M. Caldera, A. C. Huston, M. O'Brien. Social interactions and play patterns of parents and toddlers with feminine, masculine, and neutral toys, Child Development, Vol. 60, 70-76, 1989.

[9] A. McGillicuddy-De Lisi. The relationship between parental beliefs and children's cognitive level, In I. E. Sigel (Ed.), Parental Belief Systems: The Psychological Consequences for Children (pp. 7-24), Lawrence Erlbaum, Hillsdale NJ, 1985.

[10] J. Palacios, M. Gonzalez, M. Moreno. Stimulating the child in the zone of proximal development: The role of parents' ideas, In I. E. Sigel, A. V. McGillicuddy-De Lisi, J. J. Goodnow (Eds.), Families as Learning Environments for Children, 2nd ed. (pp. 71-94), Lawrence Erlbaum, Hillsdale NJ, 1992.

[11] H. L. Rheingold, K. V. Cook. The context of boys' and girls' rooms as an index of parents' behavior, Child Development, Vol. 46, 459-463, 1975.

[12] J. S. Eccles. School and family effects on the ontogeny of children's interests, self-perceptions, and activity choices, In J. E. Jacobs, R. Dienstbier (Eds.), Nebraska Symposium on Motivation: Vol. 40. Developmental Perspectives on 
Motivation (pp. 145-208), University of Nebraska Press, Lincoln, 1993.

[13] D. Howard, R. Madrigal. Who makes the decision: The parent or child? Journal of Leisure Research, Vol. 22, 244-258, 1990.

[14] J. E. Jacobs, J. S. Eccles. Parents' task values, and real-life achievement-related choices, In C. Sansone (Ed.), Intrinsic and Extrinsic Motivation: The Search for Optimal Motivation and Performance (pp. 405-439), Academic, San Diego, 2000.

[15] J. E. Jacobs, M. K.Vernon, J. S. Eccles. Activity choices in middle childhood: The roles of gender, self-beliefs, and parents' influence, In J. L. Mahoney, R. W. Larson, J. S. Eccles (Eds.), Organized Activities as Contexts of Development: Extracurricular Activities, After-Schooland Community Programs(pp. 235-254),Lawrence Erlbaum,Mahwah NJ, 2005.

[16] I. E. Sigel, A. McGillicuddy-De Lisi. Parent beliefs are cognitions: The dynamic belief systems model, In M. H. Bornstein (Ed.), Being and Becoming a Parent, 2nd ed. Handbook of Parenting, Vol. 3 (pp. 485-508), Erlbaum, Mahwah NJ, 2002.

[17] L. M. Fogle, J. L. Mendez. Assessing the play beliefs of African American mothers with preschool children, Early Childhood Research Quarterly, Vol. 21, 507-518, 2006.

[18] P. Parmar, S. Harkness, C. M. Super. Asian and Euro-American parents' ethnotheories of play and learning: Effects on preschool children's home routines and school behavior, International Journal of Behavioral Development, Vol. 28, No. 2, 97-104, 2004.

[19] W. L. Haight, R. D. Parke, J. E. Black. Mothers' and fathers' beliefs about and spontaneous participation in their toddlers' pretend play, Merrill-Palmer Quarterly, Vol. 43, No. 2, 271-290, 1997.

[20] M. E. Lamb. The Role of the Father in Child Development, 4th ed., Wiley, New York, 2004.

[21] R. D. Parke. Fatherhood, Harvard University Press, Cambridge, MA, 1996.

[22] R. D. Parke, B. J. Tinsley. Family interaction in infancy, In J. Osofsky (Ed.), Handbook of Infant Development, Wiley, New York, 1987.

[23] T. G. Power, R. D. Parke. Patterns of early socialization: Mother- and father-infant interaction in the home, International Journal of Behavioral Development, Vol. 9, 331-341, 1986.

[24] C. S. Tamis-LeMonda. Conceptualizing fathers' roles: Playmates and more, Human Development, Vol. 47, No. 4, 220-227, 2004.

[25] L. Craig. Children and the revolution: A time-diary analysis of the impact of motherhood on daily workload,Journal of Sociology, Vol. 42, 125-143, 2006.

[26] J. C. Nunnally, I. H. Bernstein. Psychometric Theory, 3rd ed., McGraw-Hill, New York, 1994.

[27] D. Baumrind. Current patterns of parental authority, Developmental Psychology Monographs, Vol. 4, No. 1, Pt. 2 , 1971.
[28] D. Baumrind. Parental disciplinary patterns and social competence in children, Youth and Society, Vol. 9, 239-276, 1978 .

[29] D. Baumrind. Rearing competent children. In W. Damon (Ed.), Child Development Today and Tomorrow (pp. 349-378), Jossey-Bass, San Francisco, 1989.

[30] D. Baumrind. Necessary distinctions, Psychological Inquiry, Vol. 8, 176-229, 1997.

[31] E. E. Maccoby, J. A. Martin. Socialization in the context of the family: Parent-child interaction, In P. H. Mussen (Ed.), Handbook of Child Psychology, 4th ed., Vol. 4, Wiley, New York, 1983

[32] R. J. Coplan, P. D., Hastings, D. G., Lagace-Seguin, C. E. Moulton. Authoritative and authoritarian mothers' parenting goals, attributions, and emotions across different childrearing contexts, Parenting: Science and Practice, Vol. 2, No. 1, 1-26, 2002.

[33] G. W. Holden, P. C. Miller. Enduring and different: A meta-analysis of the similarity in parents' child rearing, Psychological Bulletin, Vol. 125, 223-254, 1999.

[34] J. G. Smetana. Parental styles and beliefs about parental authority, New Directions for Child Development, Vol. 66, 21-36, 1994.

[35] C. Robinson, B. Mandleco, S. Olsen, C. Hart. Authoritative, authoritarian, and permissive parenting practices: Development of a new measure, Psychological Reports, Vol. 77, 819-830, 1995

[36] C. Hart, D. Nelson, C. Robinson, S. Olsen, M. MacNeilly-Choque. Overt and relational aggression in Russian nursery school age children: Parenting style and marital linkages, Developmental Psychology, Vol. 34, 687-697, 1998 .

[37] C. Hart, C. Yang, D. Nelson, S. Jin, N. Bazarskaya, L. Nelson. Peer contact patterns, parenting practices, and preschoolers' social competence in China, Russia, and the United States, In P. Slee, K. Rigby (Eds.), Peer Relations Amongst Children: Current Issues and Future Directions (pp. 3-30), Routledge, London, 1998.

[38] J. Gervai, P. J. Turner, R. A. Hinde. Gender-related behavior, attitudes, and personality in parents of young children in England and Hungary, International Journal of Behavioral Development, Vol. 18, 105-126, 1995.

[39] P. J. Turner, J. Gevai. A multidimensional study of gender typing in preschool children and their parents: Personality, attitudes, preferences, behavior, and cultural differences, Developmental Psychology, Vol. 31, No. 5, 759-772, 1995.

[40] A. T. Beck, R. A. Steer, G. K. Brown. BDI-II: Beck Depression Inventory Manual, 2nd ed., PsychologicalCorporation, San Antonio, 1996.

[41] D. Watson, L. A.Clark, A. Tellegen. Development and validation of brief measuresof Positive and Negative Affect: The PANAS scales,Journal of Personality \& Social Psychology, Vol. 54, 1063-1070, 1988.

[42] J. S. Eccles, J. S.,J. A. Gootman. Community Programs to Promote Youth Development, National Academy Press, Washington, D.C., 2002. 
[43] R. W. Larson. Toward a psychology of positive youth development, American Psychologist, Vol. 55, No. 1, 170-183, 2000.

[44] J. L. Roth, J. Brooks-Gunn. What is a youth development program? Identification of defining principles. In R. M. Lerner, F. Jacobs, D. Wertlieb (Eds.), Promoting Positive Child, Adolescent, and Family Development: A Handbook of Program and Policy Innovations, Vol. 2 (pp. 197-224), Sage, Thousand Oaks CA, 2003.

[45] P. K. Smith, R. Vollstedt. On defining play: An empirical study of the relationship between play and various play criteria, Child Development, Vol. 56, 1042-1050, 1985.

[46] A. J. Viera, J. M. Garrett. Understanding interobserver agreement: The Kappa statistic, Family Medicine, Vol. 37, No. 5, 360-363, 2005.

[47] B. L. Barber, M. R. Stone, J. E. Hunt, J. S. Eccles. Benefits of activity participation: The roles of identity affirmation and peer group norm sharing. In J. L. Mahoney, R. W. Larson, J. S. Eccles (Eds.), Organized activities as Contexts of Development: Extracurricular Activities, After-School and Community Programs(pp. 185-210), Erlbaum, Mahwah NJ, 2005.

[48] L. A. Barnett, J. J. Weber. Perceived benefits to children from participating in different types of recreational activities, Journal of Park and Recreation Administration, Vol. 26, No. $3,1-20,2008$

[49] A. C. Fletcher, P. Nickerson, K. L. Wright. Structured leisure activities in middle childhood: Links to well-being, Journal of Community Psychology, Vol. 31, No. 6, 641-659, 2003.

[50] R. W. Larson. How U. S. children and adolescents spend time: What it does (and doesn't) tell us about their development, Current Directions in Psychological Science, Vol. 10, 160-164, 2001.

[51] J. K. Posner, D. L. Vandell. Low-income children's after-school care: Are there beneficial effects of after-school programs? Child Development, Vol. 65, 440-456, 1994.

[52] J. K. Posner, D. L. Vandell. After-school activities and the development of low-income urban children: A longitudinal study, Developmental Psychology, Vol. 35, No. 3, 868-879, 1999.

[53] J. A. Naglieri. Naglieri Nonverbal Ability Test, Psychological Corporation, San Antonio, 1997. (a)

[54] J. A. Naglieri. NNAT multilevel technical manual, Psychological Corporation,San Antonio, 1997. (b)

[55] J. A. Naglieri, M. E. Ronni.Comparison of White, African American, Hispanic, and Asian Children on the Naglieri Nonverbal Ability Test, Psychological Assessment, Vol. 12, No. 3, 328-334, 2000.

[56] W. Adams, L. Erb, D. Sheslow. Test of Academic Performance Examiner's Manual,The Psychological Corporation, Toronto, 1989.

[57] Buros Institute. Test review of the Test of Academic Performance, In J. C. Impara, B. S. Plake (Eds.), The 13th Mental Measurements Yearbook, Buros Institute of Mental Measurements, Lincoln NE, 1998.
[58] R. L. Gorsuch. Exploratory factor analysis: Its role in item analysis, Journal of Personality Assessment, Vol. 68, 532-560, 1997.

[59] F. J. Floyd, K. F. Widaman. Factor analysis in the development and refinement of clinical assessment instruments, Psychological Assessment, Vol. 7, 286-299, 1995.

[60] L. R. Cote,M. H. Bornstein. Child and mother play in three U.S. cultural groups: Comparisons and associations, Journal of Family Psychology, Vol. 23, No. 3, 355-363, 2009.

[61] S. Harkness, P. O. Zylicz, C. M. Super, B. Welles-Nystrom, M. R. Bermudez, S. Bonichini, U. Moscardino, C. J. Mavridis. Children's activities and their meanings for parents: A mixed-methods study in six western cultures, Journal of Family Psychology, Vol. 25, No. 6, 799-813, 2011.

[62] D. A. Kleiber. Leisure Experience and Human Development: A Dialectical Interpretation, Basic,New York, 1999.

[63] P. M. Hu, P. M. Bentler. Cutoff criteria for fit indexes in covariance structure analysis: Conventional criteria versus new alternatives, Structural Equation Modeling, Vol. 6, 1-55, 1999.

[64] R. B. Cattell. The scree test for number of factors, Multivariate Behavior Assessment, Vol. 1, 245-276, 1966.

[65] D. George, D. P. Mallery. SPSS for Windows: A Simple Guide and Reference, 11.0 update, 4th ed.Allyn \& Bacon,Boston, 2003.

[66] D. L. Streiner. Starting at the beginning: An introduction to coefficient alpha and internal consistency, Journal of Personality Assessment, Vol. 80, 99-103, 2003.

[67] A. Anastasi,Psychological Testing, Macmillan, New York, 1988.

[68] C. H. Lawshe. A quantitative approach to content validity, Personnel Psychology, Vol. 28, 563-575, 1975.

[69] F. R. Wilson, W. Pan, D. Schumsky. Recalculation of the critical values for Lawshe's content validity ratio, Measurement and Evaluation in Counseling and Development, Vol. 45, No. 3, 197-210, 2012.

[70] M. Aickin. Other methods of adjustment of multiple testing exists,British Medical Journal, Vol. 318, 127-128, 1999.

[71] T. V. Perneger. What's wrong with the Bonferroni adjustments,British Medical Journal, Vol. 361, 1236-1238, 1998.

[72] J. Ruscio, B. Roche. Determining the number of factors to retain in an exploratory factor analysis using comparison data of known factorial structure, Psychological Assessment, Vol. 24, No. 2, 282-292, 2012.

[73] L. J. Cronbach, P. E. Meehl. Construct validity in psychological tests. Psychological Bulletin, Vol. 52, 281-302, 1955.

[74] J. Kagan. The meaning of personality predicates, American Psychologist, Vol. 43, 614-620, 1988.

[75] A. C. Fletcher, G. H. Elder Jr.,D. Mekos. Parental influence on adolescent involvement in community activities, Journal of Research in Adolescence, Vol. 10, 29-48, 2000. 
[76] J. E. Jacobs, J. S. Eccles. The influence of parent stereotypes on parent and child ability beliefs in three domains, Journal of Personality and Social Psychology, Vol. 63, 932-944, 1992.

[77] S. M. McHale, A. C. Crouter, C. J. Tucker. Family context and gender role socialization in middle childhood: Comparing boys to girls and sisters to brothers, Child Development, Vol. 59, No. 2, 990-1004, 1999.

[78] J. W. Santrock. Life-Span Development, 14th ed., McGraw-Hill, New York, 2012.

[79] J. S. Eccles, T. F. Adler, R. Futterman, S. B. Goff, C. M. Kaczala, J. L. Meece, C. Midgley. Expectancies, values, and academic behaviors, In J. T. Spence (Ed.), Achievement and Achievement Motivation (pp. 75-146), W. H. Freeman, San Francisco, 1983.

[80] A. Wigfield, J. S. Eccles. The development of achievement task values: A theoretical analysis, Developmental Review, Vol. 12, 265-310, 1992.

[81] J. S. Eccles, B. L. Barber. Student council, volunteering, basketball, or marching band: What kind of extracurricular involvement matters? Journal of Youth and Adolescence, Vol. 6, No. 3, 281-294, 1999.

[82] B. L. Barber, J. S. Eccles, M. R. Stone. Whatever happened to the jock, the brain, and the princes? Young adult pathways linked to adolescent activity involvement and social identity, Journal of Adolescent Research, Vol. 16, 429-455, 2001.

[83] R. J. Brusted, M. L.Babkes, A. L. Smith. Youth in sport: Psychological considerations, In R. N. Singer, H. A. Hausenblas, C. M. Janelle (Eds.), Handbook of Sport Psychology, 2nd ed. (pp. 604-635), Wiley, New York, 2001.

[84] R. W. Larson. Youth organizations, hobbies, and sports as developmental contexts, In E. R. K. Silberiesen, E. Todt (Eds.), Adolescence in Context: The Interplay of Family, School, Peers, and Work in Adjustment (pp. 46-65), Springer-Verlag, New York, 1994.

[85] J. L. Mahoney, A. E. Schweder, H. Stattin. Structured after-school activities as a moderator of depressed mood for adolescents with detached relations to their parents, Journal of Community Psychology, Vol. 30, 69-86, 2002.

[86] R. F. Catalano, M. L. Berglund, J. A. Ryan, H. S. Lonczak, J. D. Hawkins. Positive Youth Development in the United States: Research Findings on Evaluations of Positive Youth Development Programs, Carnegie Corporation, New York, 1999.

[87] J. L. Duda, N. Ntoumanis. After-school sport for children: Implications of a task-involving motivational climate, In J. L. Mahoney, R. W. Larson, J. S. Eccles (Eds.), Organized Activities as Contexts of Development: Extracurricular Activities, After-School and Community Programs(pp. 311-330), Erlbaum, Mahwah NJ, 2005.

[88] H. W. Marsh. Extracurricular activities: Beneficial extension of the traditional curriculum or subversion of academic goals? Journal of Educational Psychology, Vol. 84, 553-562, 1992.

[89] S. M. McHale, A. C. Crouter, C. J. Tucker. Free-time activities in middle childhood: Links with adjustment in early adolescence, Child Development, Vol. 72, No. 6, 1764-1778, 2001.

[90] M. B. Jones, D. R. Offord. Reduction of antisocial behavior in poor children by nonschool skill-development, Journal of Child Psychology and Psychiatry, Vol. 30, 737-750, 1989.

[91] J. L. Mahoney. Participation in school extracurricular activities as a moderator in the development of antisocial patterns, Child Development, Vol. 71, 502-516, 2000.

[92] G. S. Pettit, R. D. Laird, J. E. Bates, K. A. Dodge. Patterns of after-school care in middle childhood: Risk factors and developmental outcomes, Merrill-Palmer Quarterly, Vol. 43, 515-538, 1997.

[93] D. L. Vandell, L. Shumow, J. Posner. After-school programs for low-income children: Differences in program quality,In J. L. Mahoney, R. W. Larson, J. S. Eccles (Eds.), Organized Activities as Contexts of Development: Extracurricular Activities, After-Schooland Community Programs(pp. 437-456), Erlbaum, Mahwah NJ, 2005.

[94] S. A. Gerstenblith, D. A. Soule, D. C. Gottfredson, S. Lu, M. A. Kellstrom, S. C., Womer, S. L. Bryner. After-school programs, antisocial behavior, and positive youth development: An exploration of the relationship between program implementation and changes in youth behavior, In J. L. Mahoney, R. W. Larson, J. S. Eccles (Eds.), Organized Activities as Contexts of Development: Extracurricular Activities, After-School and Community Programs(pp. 457-478), Erlbaum, Mahwah NJ, 2005.

[95] R. W. Larson, S. Verma. How children and adolescents spend time across the world: Work, play, and developmental opportunities, Psychological Bulletin, Vol. 125, No. 6, 701-736, 1999.

[96] H. Schwartzman. Transformations: The Anthropology of Children's Play, Plenum, New York, 1978.

[97] S. S. Luthar, K. A. Shoum, P. J. Brown. Extracurricular involvement among affluent youth: A scapegoat for "ubiquitous achievement pressures," Developmental Psychology, Vol. 42, 583-597, 2006.

[98] J. L. Mahoney, A. L. Harris, J. S. Eccles. Organized activity participation, positive youth development, and the Over-Scheduling Hypothesis, Social Policy Report, Vol. 20, No. 4, 1-31, 2006.

[99] F. A. Villarruel, M. Montero-Sieburth, C. Dunbar, C. W. Outley. Dorothy, there is no yellow brick road: The paradox of community development approaches for Latino and African American urban youth,In J. L. Mahoney, R. W. Larson, J. S. Eccles (Eds.), Organized Activities as Contexts of Development: Extracurricular Activities, After-School and Community Programs(pp. 111-129), Erlbaum: Mahwah NJ, 2005. 